\title{
SEDIMENTOLOGICAL ANALYSES OF EGGSHELL TRANSPORT AND \\ DEPOSITION: IMPLICATION AND APPLICATION \\ TO EGGSHELL TAPHONOMY
}

by

Takuya Imai

A thesis submitted in partial fulfillment of the requirements for the degree

\author{
of \\ Master of Science \\ in \\ Earth Sciences \\ MONTANA STATE UNIVERSITY \\ Bozeman, Montana
}

May, 2013 


\section{CCOPYRIGHT}

by

Takuya Imai

2013

All Rights Reserved 


\section{APPROVAL}

of a thesis submitted by

Takuya Imai

This thesis has been read by each member of the thesis committee and has been found to be satisfactory regarding content, English usage, format, citation, bibliographic style, and consistency and is ready for submission to The Graduate School.

Dr. David J. Varricchio

Approved for the Department of Earth Sciences

Dr. David W. Mogk

Approved for The Graduate School

Dr. Ronald W. Larsen 


\section{STATEMENT OF PERMISSION TO USE}

In presenting this thesis in partial fulfillment of the requirements for a master's degree at Montana State University, I agree that the Library shall make it available to borrowers under rules of the Library.

If I have indicated my intention to copyright this thesis by including a copyright notice page, copying is allowable only for scholarly purposes, consistent with "fair use" as prescribed in the U.S. Copyright Law. Requests for permission for extended quotation from or reproduction of this thesis in whole or in parts may be granted only by the copyright holder.

Takuya Imai

May, 2013 


\section{ACKNOWLEDGEMENTS}

Present research was supported by National Science Foundation grant \#0847777 (EAR) to D. Varricchio. D. Varricchio, J. Schmitt, and J. Cahoon helped developing study design. D. Varricchio also provided ostrich eggshells. F. Jackson and J. Hayward offered comments about eggshell transport, and T. Evans about transport of organic remains. L. Turner, T. Turner, and T. Green provided emu eggshells. K. Plymesser provided a technical support for the use of Acoustic Doppler Velocimeter, and J. Bones for the use of the flume. This study benefited from discussions with J. Simon, S. Oser, D. Lawver, D. Barta, C. Heck, A. Moore-Nall, and H. Wilson. Civil Engineering Department, Montana State University, permitted an access to their flume facility. 
TABLE OF CONTENTS

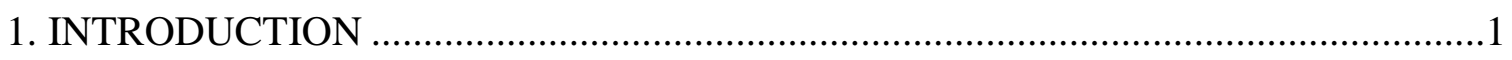

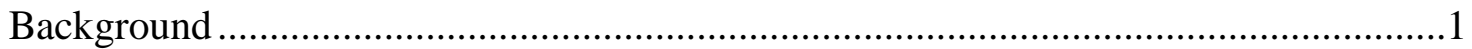

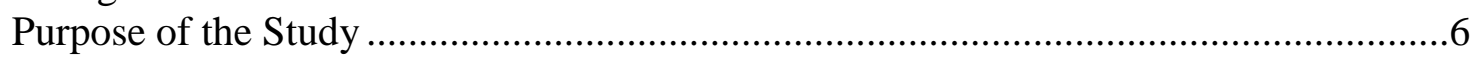

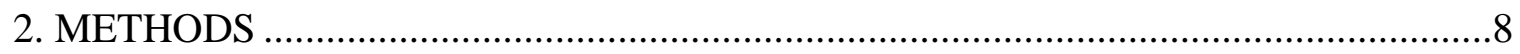

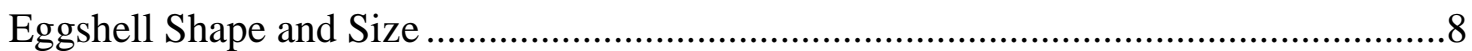

Data Collection in the Flume ............................................................................. 9

Data Analysis .................................................................................................. 11

Eggshell Orientation at Deposition ............................................................ 11

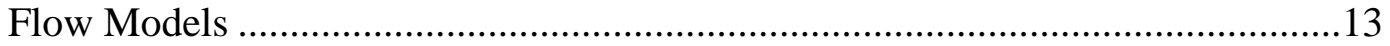

Flow Competence for Eggshell Deposition ...................................................13

Relationships of $\tau_{\mathrm{c}}$ with Eggshell Shape and Size .......................................15

Estimated Size of Clastic Particles Deposited with Eggshells.............................15

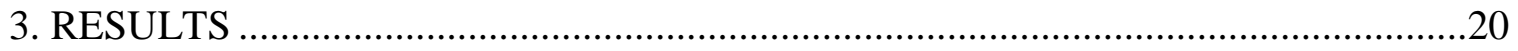

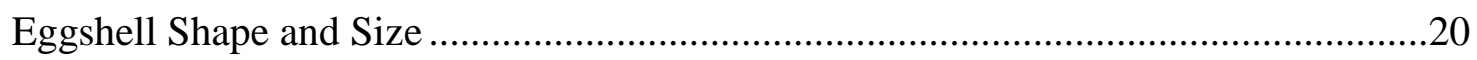

Eggshell Behaviors during Transport ....................................................................20

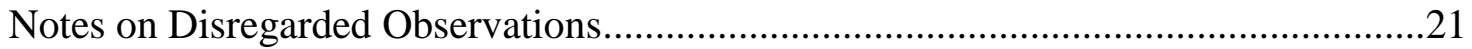

Eggshell Orientation at Deposition .......................................................................22

Relationships of $\tau_{\mathrm{c}}$ with Eggshell Shape and Size ..................................................22

Estimated Size of Clastic Particles Deposited with Eggshells...................................23

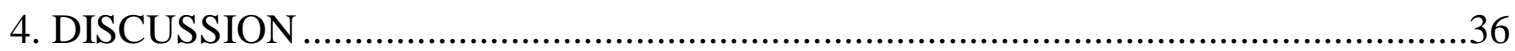

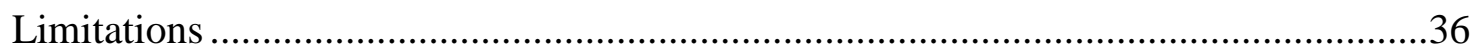

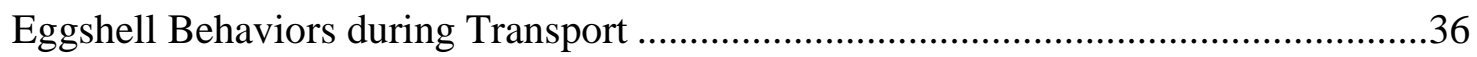

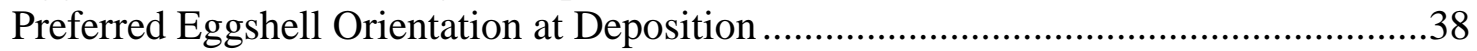

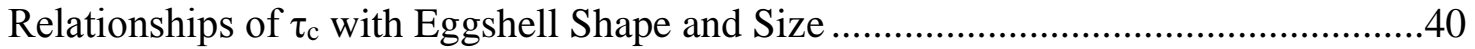

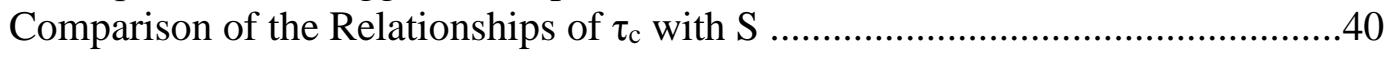

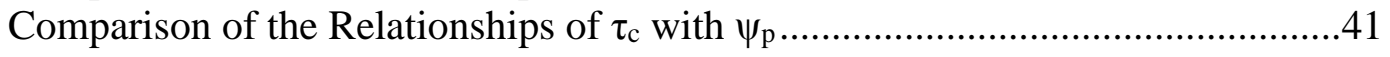

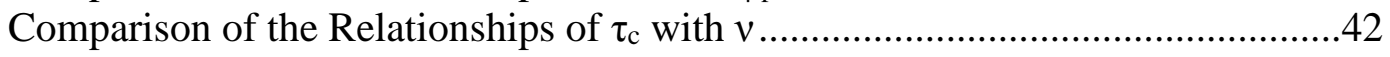

Consideration of S, $\psi_{p}$, and $v$ with a Focus on Field Application........................42

Size of Eggshell-equivalent Clastic Particles for Eggshell Deposition .........................43

Application to Field Studies...............................................................................44

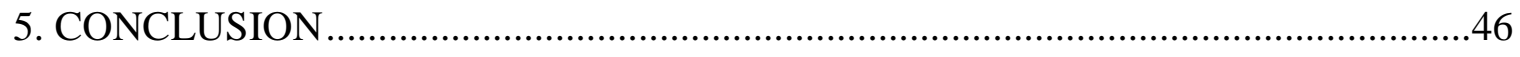

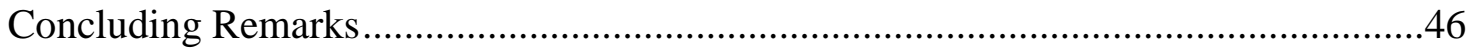


TABLE OF CONTENTS - CONTINUED

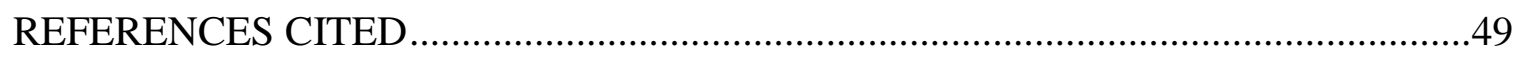

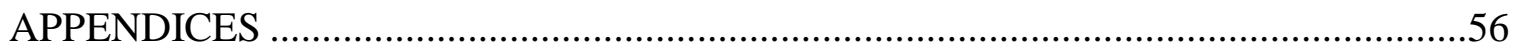

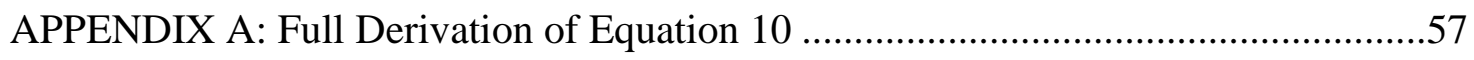

APPENDIX B: Physical Properties of Each Eggshell Used .....................................59 


\section{LIST OF TABLES}

Table $\quad$ Page

1. Inferred Eggshell Transport in Fossil Record in Past Studies ...........................

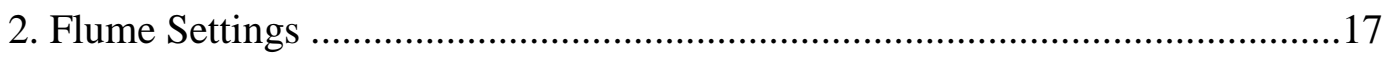

3. Averaged Physical Properties for Each Eggshell Type ...................................24

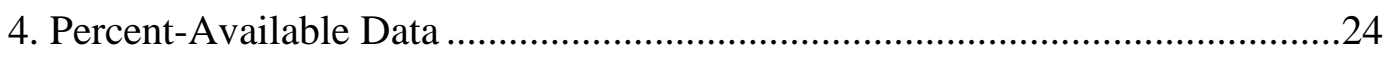

5. Relationships of $\tau_{\mathrm{c}}$ at Eggshell Deposition with Shape and Size.....................25

6. Estimated Size of Clastic Grains Deposited with Eggshells ...........................26 


\section{LIST OF FIGURES}

$\begin{array}{lll}\text { Figure } & \text { Page }\end{array}$

1. Elevation and Plan Views of a Concave-down Oriented Eggshell ...................18

2. A schematic Diagram of the Flume Setting ................................................18

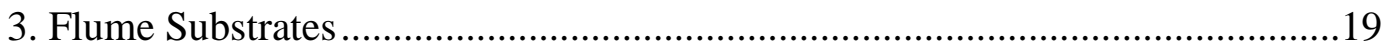

4. Schematic Diagram of Eggshell Deposition under Different Conditions..........27

5. A Stationary Eggshell under a Supercritical Flow .......................................27

6. Examples of concave-down and -up oriented ostrich eggshells .....................28

7. Estimated Probabilities of Concave-down eggshells after transport ................29

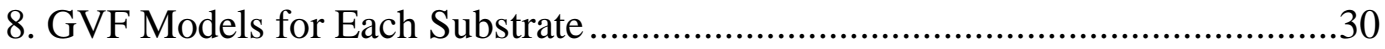

9. Plots of $\tau_{\mathrm{c}}$ vs. Natural Log of Eggshell S, $\psi_{\mathrm{p}}$, and $v$ on the Coarse Sand ..........31

10. Plots of $\tau_{\mathrm{c}}$ vs. Natural Log of Eggshell $\mathrm{S}, \psi_{\mathrm{p}}$, and $v$ on the Sparse Gravel ......32

11. Plots of $\tau_{\mathrm{c}}$ vs. Natural Log of Eggshell S, $\psi_{\mathrm{p}}$, and $v$ on the Dense Gravel.......33

12. Plots of $\tau_{\mathrm{c}}$ vs. Natural Log of Eggshell S, $\psi_{\mathrm{p}}$, and $v$ on the PVC....................34

13. Estimated Diameter of Quartz Particles to be Deposited with Eggshells ........35 


\begin{tabular}{|c|c|}
\hline A & Flow cross sectional area $\left(\mathrm{cm}^{2}\right)$ \\
\hline$d$ & Grain diameter $(\mathrm{cm})$ \\
\hline $\mathrm{Fr}$ & Froude number \\
\hline$g$ & Acceleration by gravity $\left(\mathrm{cm} / \mathrm{s}^{2}\right)$ \\
\hline I & Maximum eggshell width (cm) \\
\hline $\mathrm{L}$ & Maximum eggshell length $(\mathrm{cm})$ \\
\hline$m$ & Mass of a dry eggshell (g) \\
\hline$m_{s}$ & Mass of a water-saturated eggshell submerged in water $(\mathrm{g})$ \\
\hline$n_{b}$ & Manning's coefficient for channel bed \\
\hline$n_{s}$ & Manning's coefficient for channel sides \\
\hline $\mathrm{N}$ & Total number of measurements for each $u_{x}$ and $u_{y}$ \\
\hline Q & Flow rate $\left(\mathrm{cm}^{3} / \mathrm{s}\right)$ \\
\hline $\mathrm{R}$ & Channel hydraulic radius $(\mathrm{cm})$ \\
\hline $\mathrm{S}$ & Maximum eggshell height $(\mathrm{cm})$ \\
\hline $\mathrm{S}_{0}$ & Bed slope $(\mathrm{cm} / \mathrm{cm})$ \\
\hline$t$ & Time (sec.) \\
\hline$u$ & Bulk flow velocity $(\mathrm{cm} / \mathrm{s})$ \\
\hline$u^{*}$ & Shear velocity $(\mathrm{cm} / \mathrm{s})$ \\
\hline$u_{x}$ & Instantaneous near-bed streamwise flow velocity $(\mathrm{cm} / \mathrm{s})$ \\
\hline$u_{y}$ & Instantaneous near-bed vertical flow velocity $(\mathrm{cm} / \mathrm{s})$ \\
\hline
\end{tabular}


NOMENCLATURE - CONTINUED

$\begin{array}{ll}x & \text { Position of eggshell deposition measured from the outlet }(\mathrm{cm}) \\ y & \text { Estimated flow depth }(\mathrm{cm}) \\ y^{\prime} & \text { Measured flow depth }(\mathrm{cm}) \\ v & \text { Particle volume }\left(\mathrm{cm}^{3}\right) \\ \rho & \text { Particle density }\left(\mathrm{g} / \mathrm{cm}^{3}\right) \\ \rho_{\mathrm{w}} & \text { Water density }\left(\mathrm{g} / \mathrm{cm}^{3}\right) \\ \tau_{0} & \text { Bed shear stress based on Song and Gruf }(1995)\left(\mathrm{g} / \mathrm{cm} \cdot \mathrm{s}^{2}\right) \\ \tau_{\mathrm{c}} & \text { Critical bed shear stress at eggshell deposition based on } \tau_{0}\left(\mathrm{~g} / \mathrm{cm} \cdot \mathrm{s}^{2}\right) \\ \tau_{\mathrm{r}} & \text { Bed shear stress based on Reynolds shear }(\text { Biron et al., } 2004)\left(\mathrm{g} / \mathrm{cm} \cdot \mathrm{s}^{2}\right) \\ \psi_{\mathrm{p}} & \text { Maximum projection sphericity }\end{array}$




\begin{abstract}
The interpretation of fossil eggshell assemblages in the absence of nesting structures is problematic because eggshells can be transported by hydraulic flows in fluvial environments. Failure to recognize transported eggshells may lead to erroneous interpretation of the reproductive behavior and ecology of those animals. An inconsistent array of evidence has been used in past studies to assess eggshell transport. Here, a series of flume studies was conducted to establish analytical techniques for assessing eggshell hydraulic transport in the fossil record. Using modern eggshells in a flume, I investigated preferred eggshell orientation after transport, the relationship of flow competence with eggshell shape and size, and size of clastic sediment expected to be associated with transported eggshells. Emu, goose, and ostrich eggshell fragments were released in a rectangular flume with decelerating flow. The transport of each eggshell was observed five times on each of four substrates (coarse sand, sparse gravel, dense gravel, and polyvinyl chloride). At eggshell deposition, eggshell orientation and flow depth were recorded. Critical bed shear stress for eggshell deposition was estimated based on the flow depth at the point of eggshell deposition. The probability of concave-down orientation for deposited eggshells was estimated for each eggshell type transported on each substrate. The relationship of the critical bed shear stress for eggshell deposition with eggshell shape and size was tested. Size of clastic grains deposited under the critical bed shear stress for eggshell deposition was estimated. The probability of concave-down orientation after transport was $>85 \%$ regardless of eggshell types and substrates. The bed shear stress at eggshell deposition was most closely related to eggshell height and volume. Estimated size of clastic sediment associated with transported eggshell was coarse sand or coarser sediment. One may consider a high proportion of concave-down oriented eggshells in fossil assemblages as indicative of transport regardless of eggshell types. In addition, eggshells may be sorted according to their height and volume. Coarse sand or larger particles observed in matrix of fossil eggshells may be used as evidence of eggshell transport. Further studies are necessary to test reliability of those techniques and broaden their applicability.
\end{abstract}




\section{INTRODUCTION}

\section{$\underline{\text { Background }}$}

Studies of fossil eggshells aid our understanding of reproductive behaviors of extinct amniotes that lay hard-shelled eggs (primarily archosaurs and turtles) and reconstruction of their nesting environments. In addition, fossil eggshells facilitate stratigraphic correlations within the Neogene of African (Pickford et al., 1995; Harrison and Msua, 2005), and provide evidence for paleobiogeographic connections in the Late Cretaceous (Vianey-Liaud et al., 2003). However, the observation that fossil eggshells (fragments to nearly whole eggs) often occur in floodplains and alluvial fan deposits (e.g., Horner, 1982; Tandon et al., 1995; Mohabey, 1998; Varricchio, 1999; Codrea et al., 2002; Chiappe et al., 2003; Cojan et al., 2003; Gottfried et al., 2004; Paik et al., 2004; Zelenitsky and Therrien, 2008; Kim et al., 2009; Liang et al., 2009) complicates interpreting these fossils. As observed in modern bird colonies, hydraulic currents (e.g., sheet floods) may influence eggshells prior to final burial (Tomkins, 1959; Sidle et al., 1992; Peresbarbosa and Mellink, 2001). Therefore, assessing transport and understanding its potential influence are essential in interpreting the paleobiology of extinct egg-laying amniotes and the biostratigraphic significance of eggshells. However, analytical techniques to address eggshell transport in the fossil record are poorly established.

A transported eggshell assemblage (parautochthonous or allochthonous sensu Behrensmeyer and Hook [1992]) represents a group of eggshells that were spatially and/or temporally disturbed, as commonly seen in fossil skeletal assemblages 
(Behrensmeyer et al., 2000). For example, spatial disturbance of eggshells may result in relocation out of a nest or removal from a nesting ground. Temporal disturbance through reworking and transport may result in an assemblage of eggshells from different nesting seasons. In such cases, inferring site fidelity within a single nesting ground can be problematic. Failure to recognize transport of an eggshell assemblage may result in erroneous interpretations of the reproductive biology of the extinct egg-laying amniotes.

Discrimination between in situ and transported eggshell assemblages can be challenging without identifiable nesting structures. In addition, limited understanding of the mechanisms and consequences of eggshell transport impede in-depth analyses of potentially transported fossil eggshell assemblages.

Despite these difficulties, some past studies have addressed the extent of eggshell transport reflected in fossil assemblages (Table 1). Erben et al. (1979) inferred a redeposited allochthonous eggshell assemblage based on eroded surfaces at the base of the eggshell-bearing conglomerate. Liang et al. (2009) used associated pebbly sediment as evidence to suggest eggshell transport and deposition under a high flow regime. Kennedy (1997) inferred synchronous deposition of eggshells with silt and mud that formed undisturbed, thinly laminated, eggshell-bearing overbank deposits. Kennedy (1997) used the following evidence for the eggshell transport: $53 \%$ of the eggshell fragments showing concave-down orientation, undisturbed nature of eggshell-bearing beds, and absence of eggshells in lower layers. Eberth (1990) reported fossil eggshells in a crevasse-splay deposit and suggested pre-burial transport based on high proportion of concave-down orientation in associated invertebrate shells. Hirsch and Quinn (1990), 
Maxwell and Horner (1994), and Sankey (2005) hypothesized transport of eggshells on a floodplain from multiple nesting sites based on the variety of eggshell morphologies represented in the assemblage. Dyke et al. (2012) reported accumulation of late Cretaceous bird eggshells mixed with complete eggs and bone fragments within a lens of calcareous mud. Dyke et al. (2012) suggested eggshell deposition following shortdistance transport from a river bank or sand bar into a shallow pond during a flood. Oser (in review) showed that eggshells recovered from a crevasse-splay deposit in the Dinosaur Park Formation (Eberth, 1990) exhibited edge rounding consistent with transported material. Moreno-Azanza et al. (in press) reported fossil eggshells in a deposit of a small ephemeral lake or pond, and interpreted them as having been transported short distances into the lake or pond before burial.

These studies used different evidence to assess eggshell transport, including: grain size of associated sediment, eggshell orientation, orientation of associated invertebrate shells, and multiple egg taxa represented in an assemblage. As a result, it is difficult to compare the studies to test their interpretations about the transport. Additionally, how eggshell can occur in deposits representing various energy conditions (channels to crevasse-splays to overbank) remains unexplained. Thus, it is necessary to establish the analytical techniques that can be used consistently to address eggshell transport, and infer depositional conditions in the fossil record.

Assessing the evidence of transport (e.g., sorting, preferred orientation, breakage, and abrasion) is a common technique used for skeletal remains in vertebrate taphonomy (Behrensmeyer, 1990 and references therein) and this principle may be applicable to 
eggshells. In addition to Oser's (in review) study where eggshell abrasion was investigated to assess eggshell transport, Hayward et al. (2011) observed the orientation of chicken eggshells deposited by unidirectional current. Hayward et al. (2011) reported preferred concave-down orientation of eggshells that have been transported by hydraulic current. Further, Hayward et al. (2011) suggested that eggshell transport may be recognized by a majority of concave-down eggshells in an assemblage. However, the study by Hayward et al. (2011) has limited applicability to fossil eggshells. The shape and size of eggshells observed in the fossil record can be dissimilar to those of chicken eggshells. Problematically, there is currently no evidence that non-chicken eggshell have preferred concave-down orientation after transport. In addition, Hayward et al. (2011) observed preferred concave-down orientation of chicken eggshells on immobile asphalt shingle and a natural sandy channel substrate. However, it is unknown whether this orientation is observable for eggshells transported on different substrates. Therefore, it is necessary to confirm that concave-down orientation is preferred for eggshells of different types transported on various substrates. If eggshells are deposited concave-down frequently regardless of their types and substrates, this use of eggshell orientation can be more confidently applied to fossil eggshells.

Eggshell shape and size may also play an important role in potential eggshell sorting. Sorting is a commonly-used sign of transport in vertebrate bones (Behrensmeyer, 1982). On the other hand, the effects of particle shape have long been of interest to researchers attempting to model particle transport (e.g., Wadell, 1932; Krumbein, 1941; Bridge, 1992; Gogus and Defne, 2005). Thus, hypothesizing a transported eggshell 
assemblage by sorting perhaps requires considerations of both size and shape. For example, if eggshell shape has a major role on eggshell transport, eggshell sorting may not be easily recognizable based on limited size distribution of eggshells in an assemblage. To the contrary, if size determines which eggshells are preferentially moved by a hydraulic flow, an eggshell assemblage with a limited shell size range may indicate transport. Testing whether size sorting can be used to distinguish transported eggshells in the fossil record requires investigation into the effects of eggshell shape and size on transport.

Another possible analytical technique for the assessment of eggshell transport is to examine the size fraction of clastic sediment associated with fossil eggshells, and compare the flow competence that likely deposited the sediment with that for the eggshells. This technique is based on the Behrensmeyer's (1975) principle of relating the size of clastic sediment to transported biological remains, e.g. vertebrate bones. This technique requires knowledge of the flow competence for eggshell deposition and estimation of the size of the sedimentary particles to be deposited at that competence (the eggshell-equivalent particles). Knowing eggshell-equivalent particles permits reevaluation of eggshell assemblages and the size of associated sedimentary particles in previous studies (e.g., Erben et al., 1979; Kennedy, 1997; Maxwell and Horner, 1994; Liang et al., 2009; Dyke et al., 2012). Presence of eggshell-equivalent particles in the associated sediment argues that a flow transported and then deposited the eggshells and the particles. 


\section{Purpose of the Study}

To answer the above questions and develop more rigorous methods to assess eggshell transport in the fossil record, I conducted a laboratory study in a controlled setting. Through a series of flume trials using eggshells of the size and shape typically reported in potentially transported eggshell assemblages, the present study tests whether: 1) preferred concave-down orientation at eggshell deposition occurs in non-chicken eggs of different size and shape, 2) relationships exist between the flow competence at eggshell deposition and eggshell shape, size, or both, and 3) the size of eggshellequivalent particles can be estimated and applied to the fossil record. 
Table 1: Past studies where eggshell transport was inferred in fossil record. Taxa refer to eggshell taxa represented in an assemblage and orientation refers to ratio of concave-down : concave-up oriented eggshells in an assemblage.

\begin{tabular}{|c|c|c|c|c|c|c|}
\hline References & Taxa & Size Range & Orientation & Sedimentology & Setting & Interpretation \\
\hline $\begin{array}{l}\text { Erben et al., } \\
1979\end{array}$ & $\begin{array}{l}\text { "Hypselosaurus } \\
\text { eggs" }\end{array}$ & Unknown & Unknown & $\begin{array}{l}\text { Hard conglomerates with } \\
\text { eroded surfaces }\end{array}$ & $\begin{array}{l}\text { Inland basin with } \\
\text { temporal rivers }\end{array}$ & $\begin{array}{l}\text { Redeposited allochthonous } \\
\text { origin }\end{array}$ \\
\hline $\begin{array}{l}\text { Erben et al., } \\
1979\end{array}$ & $\begin{array}{l}\text { "Hypselosaurus } \\
\text { eggs" }\end{array}$ & Unknown & Unknown & $\begin{array}{l}\text { Grey, cross-bedded sand stones } \\
\text { and conglomerates }\end{array}$ & $\begin{array}{l}\text { Inland basin with } \\
\text { temporal rivers }\end{array}$ & $\begin{array}{l}\text { Eroded allochthonous } \\
\text { fragments }\end{array}$ \\
\hline $\begin{array}{l}\text { Kennedy, } \\
1997\end{array}$ & Spheroolithus* & Unknown & $53: 47$ & $\begin{array}{l}\text { Fine silt to clay-size, laminated } \\
\text { to thinly bedded, muds }\end{array}$ & Crevasse splay & $\begin{array}{l}\text { Transported and settled } \\
\text { with muds }\end{array}$ \\
\hline Eberth, 1990 & Unknown & $<1 \mathrm{~cm}$ & Unknown & $\begin{array}{l}\text { Contorted lenses and laminae } \\
\text { of silty, fine-medium sandstone }\end{array}$ & Crevasse splay & $\begin{array}{l}\text { Small fragments } \\
\text { transported short distance }\end{array}$ \\
\hline $\begin{array}{l}\text { Hirsch and } \\
\text { Quinn, } 1990\end{array}$ & Continuoolithus & $\begin{array}{l}242-320 \\
\mathrm{~mm}^{2}\end{array}$ & Unknown & Unknown & Unknown & $\begin{array}{l}\text { Transported or derived } \\
\text { from nesting areas }\end{array}$ \\
\hline $\begin{array}{l}\text { Hirsch and } \\
\text { Quinn, } 1990\end{array}$ & Multiplee & Unknown & Unknown & Unknown & Unknown & $\begin{array}{l}\text { Transported or derived } \\
\text { from mixed nesting sites }\end{array}$ \\
\hline $\begin{array}{l}\text { Maxwell and } \\
\text { Horner, } 1994\end{array}$ & Multiple & Unknown & Unknown & Grey mudstone & Overbank & $\begin{array}{l}\text { Washed in with skeletons } \\
\text { of multiple taxa }\end{array}$ \\
\hline $\begin{array}{l}\text { Liang et al., } \\
2009\end{array}$ & Multiple & Unknown & Unknown & $\begin{array}{l}\text { Conglomerates and pebble- } \\
\text { bearing sandstones }\end{array}$ & $\begin{array}{l}\text { Alluvial proximal } \\
\text { fans }\end{array}$ & $\begin{array}{l}\text { Transported long-distance } \\
\text { by a strong flow }\end{array}$ \\
\hline $\begin{array}{l}\text { Dyke et al., } \\
2012\end{array}$ & $\begin{array}{l}\text { "Enantiornithian } \\
\text { eggs" }\end{array}$ & $\begin{array}{l}3.6 \mathrm{~cm} \text { in } \\
\text { average } \\
\text { length }\end{array}$ & Unknown & A lens of calcareous mudstone & $\begin{array}{l}\text { Small, shallow } \\
\text { pond }\end{array}$ & $\begin{array}{l}\text { Short-distance transport in } \\
\text { a single flooding }\end{array}$ \\
\hline $\begin{array}{l}\text { Moreno- } \\
\text { Azanza et al., } \\
\text { in press }\end{array}$ & $\begin{array}{l}\text { Trigonoolithus } \\
\text { amoae oogen. et } \\
\text { oosp. nov. }\end{array}$ & Unknown & Unknown & Clay & $\begin{array}{l}\text { Small ephemeral } \\
\text { lake or pond }\end{array}$ & $\begin{array}{l}\text { Possible short -distance } \\
\text { transport }\end{array}$ \\
\hline
\end{tabular}




\section{METHODS}

\section{Eggshell Shape and Size}

Eggshell samples included 24 fragments each of farm-produced emu (Dromaius novaehollandiae), goose (Anser anser domesticus), and ostrich (Struthio camelus). The eggshells included intact membranes to mimic natural conditions (Hayward et al., 2000).

To quantify shape, eggshells were oriented concave-down and their dimensions measured along three mutually perpendicular axes. These included the longest axis measured across the concave-down oriented shell in a plan view (L), the maximum width that was perpendicular to $\mathrm{L}$ across the sample in plan view (I), and the maximum height that was mutually perpendicular to L and I in elevation view (S) (Figure 1). Using L, I, and $\mathrm{S}$, the maximum projection sphericity $\left(\psi_{\mathrm{p}}\right)$ was calculated as (Sneed and Folk, 1958):

$$
\psi_{p}=\sqrt[3]{\frac{S^{2}}{(L \cdot I)}}
$$

Although it is arguable that concave eggshell shape does not resemble the shape of sedimentary particles, $\psi_{\mathrm{p}}$ is widely accepted parameters in sedimentological studies (Boggs, 2006, pp. 582-583). It allowed characterization of eggshell shape through simple measurements of three axes.

In this study, particle volume (v) was used to represent eggshell size. To calculate $v$, the eggshells were air dried at room temperature for five days and their mass $(m)$ measured. Then, the eggshells were soaked in water for five days to ensure complete saturation and the mass of each eggshell was measured under water at $18^{\circ} \mathrm{C}\left(m_{s}\right)$ (adapted from Butler, 1994). The particle density of an eggshell ( $\rho$ ) was calculated as: 
$\rho=\rho_{w} \frac{m}{\left(m-m_{s}\right)}$

where $\rho_{\mathrm{w}}$ is water density at $18^{\circ} \mathrm{C}$, and $v$ as:

$v=\frac{m}{\rho}$

\section{Data Collection in the Flume}

The rectangular flume is housed in the Civil Engineering Department at Montana State University, MT. The flume is $970 \mathrm{~cm}$ long, $30 \mathrm{~cm}$ tall, and $46 \mathrm{~cm}$ wide, and constructed with PVC sides and bottom with Manning's coefficients ( $n_{s}$ and $n_{b}$, respectively) of 0.0095 (Figure 2). Water temperature of the flow was approximately $20^{\circ} \mathrm{C}$ in this study. A gradually varied flow with decreasing bulk flow velocity $(u)$ downstream, i.e. decelerating flow, was created, using sharp-crested weirs placed at the flume outlet and a sluice gate upstream near the inlet (Figure 2). This setting also caused a supercritical flow upstream and subcritical flow downstream separated by a hydraulic jump (Figure 2), which produced an abrupt rise of water when the state of a flow transitioned from supercritical to subcritical (Chow, 1959, pp. 393-396). The supercritical and subcritical flow states were confirmed by calculating Froude numbers $(F r)$ of each flow as (Chow, 1959, p. 45):

$$
F r=\frac{u}{\sqrt{g \cdot y^{\prime}}}
$$

where $y^{\prime}$ is observed depth and $g$ is gravitational acceleration. In equation $4, u$ was calculated as the flow rate $(\mathrm{Q})$ divided by cross-sectional area of the flow (A):

$$
u=\frac{Q}{A}=\frac{Q}{0.46 y^{\prime}}
$$


In equation 4, if $F r<1$, the flow is classified subcritical, and if $F r>1$, the flow is classified supercritical (Chow, 1959, p. 45) (Table 2).

Eggshell transport was simulated under four immobile substrates including coarse sand, sparse gravel, dense gravel, and polyvinyl chloride (PVC). The coarse sand substrate was simulated with Mineral Surfaced Roll Roofing (G.A.P. Roofing, Inc.) made of angular, coarse-sand-sized ceramic grains adhered onto one side of a fiberglass sheet. The roofing was stapled particle-side-up on flat sheets of plywood fixed on the flume bed with silicon sealant (Figure 3A). The sparse gravel substrate was simulated with approximately $90 \mathrm{~cm}$-long concrete panels on the flume bottom, with rounded gravel (0.20 to $1.0 \mathrm{~cm}$ in diameter) sparsely embedded (Figure 3B). The dense gravel substrate was simulated as in the sparse gravel substrate except that the gravel was more densely embedded (Figure 3C). The PVC substrate employed PVC bottom of the flume (Figure 3D) as a virtually frictionless condition.

For each substrate, the bed slope $\left(\mathrm{S}_{0}\right), \mathrm{Q}$, and the weir were modified so that the eggshells were deposited between the hydraulic jump and the outlet (Table 2 and Figure 2). Each trial started with releasing six water-saturated eggshells of the same taxa at a point $10 \mathrm{~cm}$ upstream from the hydraulic jump, and eggshell movement was then observed until deposition in the subcritical flow. After five minutes, the eggshells no longer exhibited transport, except slow creeping movements that usually ended within 1 $\mathrm{cm}$. The orientation at deposition (concave-down or concave-up), and the position in the flume of each eggshell relative to the inlet $(x)$ were then recorded. An eggshell deposited less than $2 \mathrm{~cm}$ away from the flume sides during a trial was disregarded because flow 
velocity close to the walls was likely lower than $u$ due to wall drag (Bilgil, 2003). Trials were repeated until five valid orientation and $x$ data were collected for the eggshells that moved past the hydraulic jump. Following trials, $y^{\prime}$ was recorded at $90 \mathrm{~cm}$ intervals from the outlet to the hydraulic jump

Note that in this study, eggshell deposition was defined as a visual absence of eggshell movement. Although past studies have proposed different definitions for absence of particle transport, they require statistical treatment of a population of particles (Buffington and Montgomery, 1997) and were unsuitable for this study where there were only six moving particles per trial.

\section{$\underline{\text { Data Analysis }}$}

\section{Eggshell Orientation at Deposition}

To assess preferred concave-down orientation at deposition, the Generalized Estimation Equation model (Liang and Zeger, 1986) were constructed with R-Software (Carey, 2012; The R Foundation for Statistical Computing, 2012) with eggshell types and substrates as categorical variables;

$\log \left(\frac{\pi}{1-\pi}\right)=\beta_{0}+\beta_{1}$ TYPE $+\beta_{2}$ SUBSTRATE

In equation $6, \pi$ was the probability that an eggshell of a TYPE (emu, goose, or ostrich) was deposited concave-down on a SUBSTRATE (coarse sand, sparse gravel, dense gravel, or PVC), and $\beta_{0}, \beta_{1}$, and $\beta_{2}$, were regression coefficients. The Generalized Estimation Equation model (Liang and Zeger, 1986) was employed because the observations of orientation were correlated within an eggshell due to repeated trials of the 
same shell. This correlation violated an assumption of binomial logistic regression models that each observation was independent to each other. The Generalized Estimation Equation model (Liang and Zeger, 1986) took this correlation of trials within an eggshell into account by calculating the unstructured correlation between each trial within the eggshell.

For example, setting emu eggshell and the coarse sand substrate for the reference levels for TYPE and SUBSTRATE, respectively, the Generalized Estimation Equation model (Liang and Zeger, 1986) tested a null hypothesis; the probability of an emu eggshell deposited concave-down on the coarse sand substrate is equal to the probability of the same eggshell deposited concave-up (i.e., an emu eggshell does not have preferred orientation at deposition on the coarse sand substrate).

When emu and coarse sand were the reference levels, TYPE $=$ SUBSTRATE $=0$ and equation 6 became;

$\log \left(\frac{\pi}{1-\pi}\right)=\beta_{0}$

Thus, rejection of the null hypothesis was determined based on the $p$-values for $\beta_{0}$ at $\alpha=$ 0.05 . By equation $7, \pi$ was estimated as:

$\frac{\pi}{(1-\pi)}=e^{\beta_{0}}$

and

$\pi=\frac{e^{\beta_{0}}}{1+e^{\beta_{0}}}$

This procedure was performed for all combinations of eggshell types and substrates (12 combinations). 
$\underline{\text { Flow Models }}$

For each of the four substrates, a one-dimensional gradually-varied flow hydraulic model (the GVF models) was constructed. The GVF models were calibrated based on $y$ ' by changing $n_{b}$ through trial and error, but only within the range of expected $n_{b}$ values for appropriate substrates presented in Chow (1959, Table 5-6). The models enabled accurate estimates of depth $(y)$ based on $x$ for every eggshell deposited. As opposed to $y^{\prime}, y$ estimated by the GVF models was preferred because it smoothed undulations and surface waves that were difficult to measure with the point gauge.

\section{Flow Competence for Eggshell Deposition}

Flow competence for particle transport is typically expressed in terms of the bed shear stress $\left(\tau_{0}\right)$ (Wilcock, 1992). The present study employed this convention and defined the flow competence for eggshell deposition as $\tau_{0}$ at which a given eggshell ceased transport $\left(\tau_{c}\right)$.

Among several models proposed to estimate $\tau_{0}$, the model to estimate $\tau_{\mathrm{c}}$ in this study was adapted from Song and Graf (1995) but with the term for unsteady flow removed:

$\tau_{c}=\left[S_{0}-\frac{\Delta y}{\Delta x}\left(1-F r^{2}\right)\right] \rho_{w} g R \quad(10)$

where R was hydraulic radius of the flow at each eggshell deposition (see Appendix A for a full derivation of equation 10). For the rectangular flume in this study (flume width $=46 \mathrm{~cm}), \mathrm{R}$ was calculated as (Chow, 1959, Table 2-1):

$R=\frac{0.46 y}{0.46+2 y}$ 
At a given $x, \Delta y / \Delta x$ was approximated by using the centered finite-divided-difference fomula as (Chapra and Canale, 1989: Figure 23.3):

$\frac{\Delta y}{\Delta x}=\frac{y_{x+1}-y_{x-1}}{2 x}$

where $y_{x+1}$ and $y_{x-1}$ were $y$ at $(x+30 \mathrm{~cm})$ and $(x-30 \mathrm{~cm})$, respectively. Therefore, by equations $4,5,10,11$, and $12, \tau_{\mathrm{c}}$ was function of two variables, $x$ and $y$, as:

$\tau_{c}=\left[S_{0}-\frac{y_{x+1}-y_{x-1}}{2 x}\left(1-\frac{Q^{2}}{(0.46 y)^{2} g y}\right)\right] \rho_{w} g \frac{0.46 y}{0.46+2 y}$

The $\tau_{\mathrm{c}}$ used in analyses was that of equation 13 averaged typically over all successful replicates per eggshell. Song and Chiew (2001) demonstrated good agreement for estimated $\tau_{0}$ between the model of Song and Graf (1995) and the Reynolds shear model of Biron et al. (2004) that employed direct measurements of flow turbulence.

For confidence that equation 13 was appropriate in the present study, the Reynolds shear was calculated by measuring instantaneous near-bed streamwise and vertical velocity ( $u_{x}$ and $u_{y}$, respectively) fluctuations using an Acoustic Doppler Velocimeter (ADV) at five points along the flow at $3.0 \mathrm{~cm}$ above the bed over five minutes at each point. Using the ADV-measured $u_{x}$ and $u_{y}$ values, $\tau_{0}$ by the Reynolds shear $\left(\tau_{\mathrm{r}}\right)$ could be calculated as (Biron et al., 2004):

$\tau_{r}=-\rho_{w}\left\langle u_{x} u_{y}\right\rangle \quad(14)$ where $\left\langle u_{x} u_{y}\right\rangle$ denoted the covariance of $u_{x}$ and $u_{y}$ :

$\left\langle u_{x} u_{y}\right\rangle=\frac{\sum u_{x} u_{y}}{N-1}-\frac{\sum u_{x} \sum u_{y}}{N(N-1)}$

and $\mathrm{N}$ is the total number of measurements for $u_{x}$ and $u_{y}$ over five minutes. 
Relationships of $\tau_{\mathrm{c}}$ with

Eggshell Shape and Size

Using R-Software (The R Foundation for Statistical Computing, 2012), regression analyses were performed to test relationships between $\tau_{\mathrm{c}}$ at eggshell deposition and natural $\log$ of $\psi_{\mathrm{p}}, \mathrm{S}$, and $v$ against a null hypothesis; there is no relationships between $\tau_{\mathrm{c}}$ and $\psi_{\mathrm{p}}, \mathrm{S}$, or $v$. Rejection of the null hypothesis was determined with two-sided p-values at $\alpha=0.05$. The tests were performed for combinations of each eggshell type and substrate.

\section{Estimated Size of Clastic Particles}

Deposited with Eggshells

Based on averaged $\tau_{\mathrm{c}}$, it was possible to estimate the diameter of eggshellequivalent clastic particles $(d)$ to be deposited with eggshells. Using numerous data on incipient motion of clastic particles, Paphitis (2001) fit curves that represented mean $\tau_{0}$ where grains of given size were at the threshold of motion. The spherical quartz grains have $\tau_{0}$ at the threshold of motion at $20^{\circ} \mathrm{C}$ in clear water as (Paphitis, 2001):

$$
\tau_{0}=13.804\left(d^{0.512}\right) \quad(16)
$$

for $d \leq 0.10 \mathrm{~cm}$, and

$$
\tau_{0}=58.479\left(d^{1.139}\right)
$$

for $d \geq 0.10 \mathrm{~cm}$. When $d=0.10 \mathrm{~cm}, \tau_{0}=4.246 \mathrm{~g} / \mathrm{cm} \cdot \mathrm{s}^{2}$. Therefore, for $\tau_{\mathrm{c}} \leq 4.246$

$\mathrm{g} / \mathrm{cm} \cdot \mathrm{s}^{2}$ at eggshell deposition:

$$
d=\sqrt[0.152]{\frac{\tau_{0}}{13.804}}
$$

and for $\tau_{\mathrm{c}} \geq 4.246 \mathrm{~g} / \mathrm{cm} \cdot \mathrm{s}^{2}$ at eggshell deposition, 
$d=\sqrt[1.139]{\frac{\tau_{0}}{58.479}} \quad(19)$

Clastic particles whose diameters were close to the $d$ calculated by equation 18 and 19 were expected to be deposited with eggshells at given $\tau_{\mathrm{c}}$. Paphitis (2001) plotted the above relationship between $d$ and $\tau_{0}$ on a simple diagram with two slopes based on equations 16 and 17. Observed $\tau_{\mathrm{c}}$ in this study was plotted on the diagram (Paphitis, 2001) for each eggshell type transported on each substrate. 
Table 2: Flume settings for the coarse sand (CS), sparse gravel (SG), dense gravel (DG), and polyvinyl chloride (PVC) substrates installed. $\mathrm{Q}=$ flow rate, $\mathrm{S}_{0}=$ bed slope, $F r_{u}=$ Froude number at the initial depth of the hydraulic jump, $F r_{d}=$ Froude number at the sequent depth of the hydraulic jump, and $n_{b}=$ Manning's coefficients for substrates.

\begin{tabular}{|cccccccc|}
\hline Substrate & Sluice Gate & $\begin{array}{c}\text { Weir } \\
\text { Height }(\mathrm{cm})\end{array}$ & $\mathrm{Q}\left(\mathrm{cm}^{3} / \mathrm{s}\right)$ & $\mathrm{S}_{0}(\mathrm{~cm} / \mathrm{cm})$ & $F r_{u}$ & $F r_{d}$ & $n_{b}$ \\
\hline \hline CS & No & 0.09 & 26610 & 0.0138 & 1.382 & 0.499 & 0.015 \\
SG & Yes & 0.09 & 18994 & 0.0153 & 5.044 & 0.337 & 0.025 \\
DG & Yes & 0.09 & 12024 & 0.0146 & 2.074 & 0.370 & 0.035 \\
PVC & Yes & 0.21 & 16922 & 0.0133 & 1.334 & 0.324 & 0.0095 \\
\hline
\end{tabular}




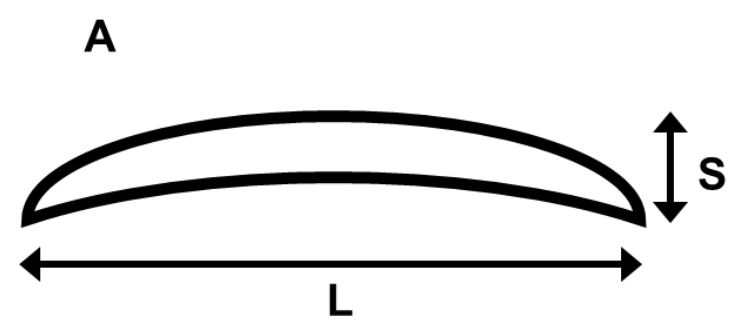

B

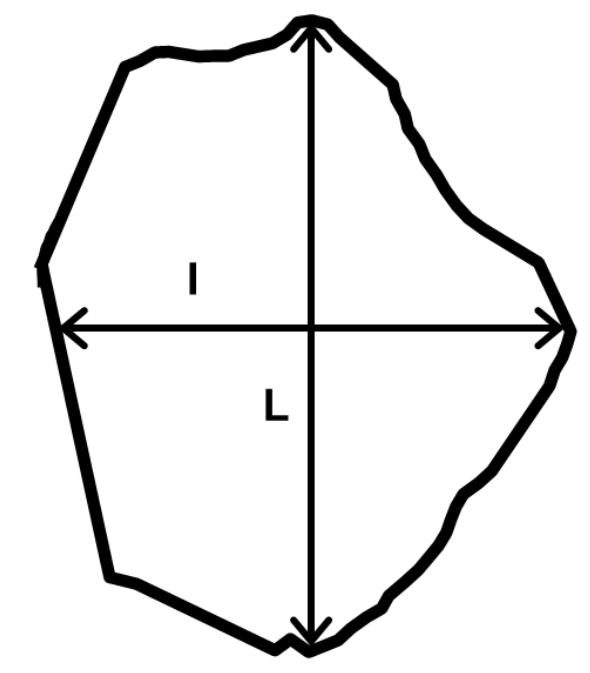

Figure 1: Elevation (A) and plan (B) views of a concave-down oriented eggshell with a longest axis (L), intermediate axis perpendicular to L (I), and height (S) shown.
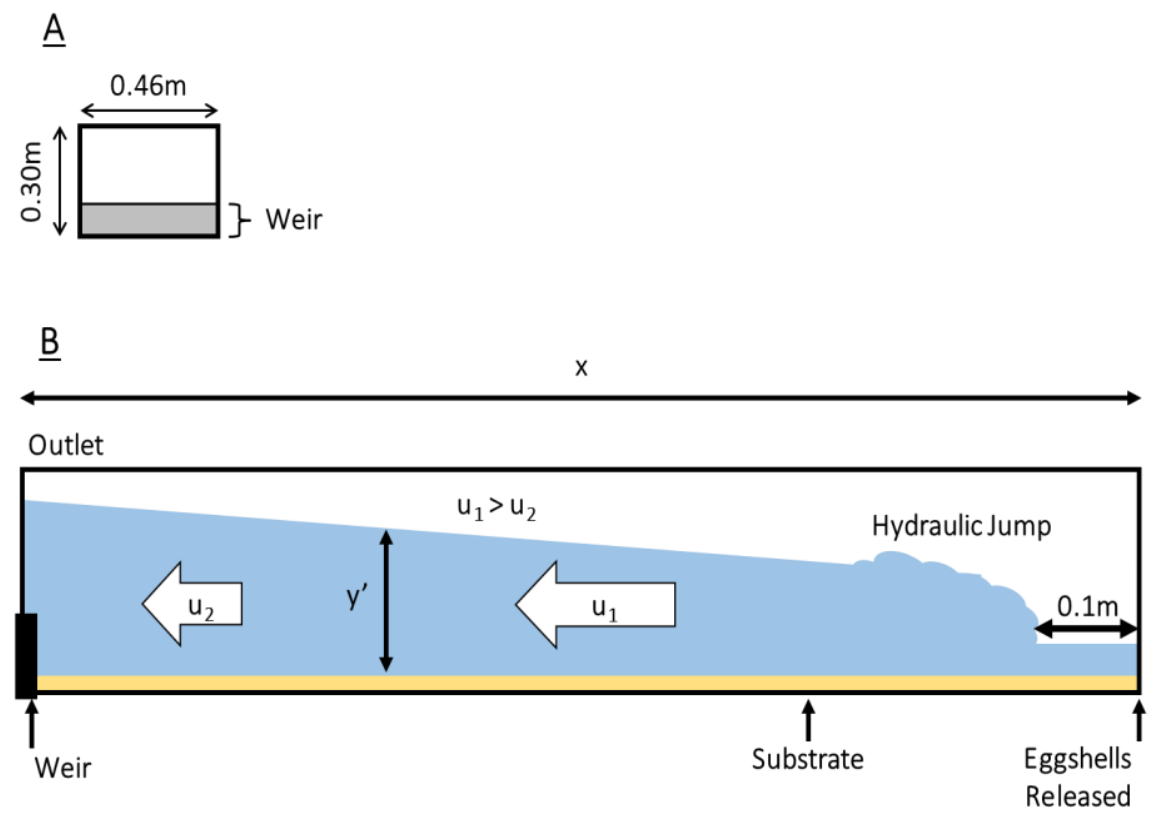

Figure 2: A schematic diagram of the flume setting, viewed from the outlet (A) and side (B). Not to scale. The water is flowing from right to left. Note the abrupt increase in flow depth at the hydraulic jump. Also, note downstream increase in flow depth $\left(y^{\prime}\right)$ and associated decrease in flow velocity $\left(u_{1}\right.$ and $\left.u_{2}\right)$ at a given flow rate. 


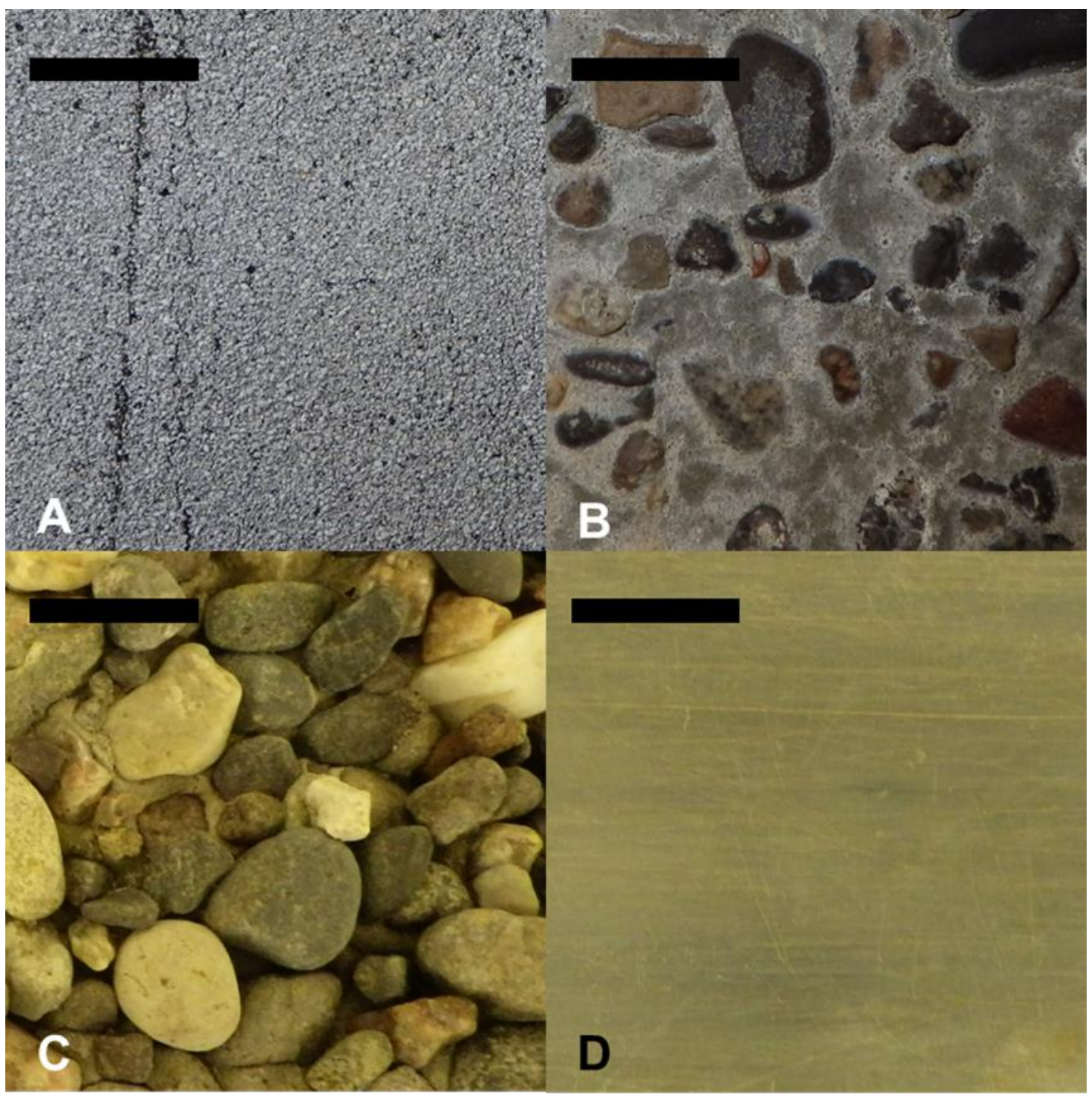

Figure 3: Flume substrates: coarse sand (A), sparse gravel (B), dense gravel (C), and PVC (D) in a plan view. Scale bars $=1 \mathrm{~cm}$. 


\section{RESULTS}

\section{Eggshell Shape and Size}

The goose eggshells had larger $\psi_{\mathrm{p}}$ on average than emu and ostrich eggshells; that is, they were taller in a concave-down orientation for a given L range (Table 3). In contrast, ostrich eggshells were larger in $v$ in general than emu and goose eggshells due to greater shell thickness (Table 3). Appendix B presents the physical properties of each eggshell used in this study.

\section{Eggshell Behaviors during Transport}

On the coarse sand substrate, the eggshells moved mostly by saltation after passing through the hydraulic jump. As $\tau_{0}$ decreased, eggshell movement shifted to primarily rolling, although sliding was occasionally observed. On the sparse and dense gravel substrate, the dominant mode of transport was saltation immediately downstream from the hydraulic jump, whereas rolling occurred further downstream. Sliding was nearly negligible. Eggshells with small L sometimes became trapped within the spacing of individual gravel particles in the sparse gravel substrate; those eggshells occasionally moved by rolling over those gravels on their way downstream. On the PVC substrate, the eggshells started sliding after passing the hydraulic jump, and rolling was infrequent.

Sliding occurred mostly when eggshells were oriented concave-down. However, eggshells did occasionally retain concave-up orientation and consequently, slid for a long distance. Notably, when this occurred, the eggshells were deposited at significantly lower 
$\tau_{0}$ than that of the eggshells that slid concave-down. Eggshell deposition was observed when either the upstream or downstream sides of the eggshells were caught by projecting particles, or when the flow was incompetent to move eggshells that were free from obstacles (Figure 4).

\section{$\underline{\text { Notes on Disregarded Observations }}$}

Some trials had to be disregarded for the analyses of preferred eggshell orientation and $\tau_{\mathrm{c}}$ estimates at eggshell deposition. This was because the eggshells either did not pass the hydraulic jump after the release, traveled to the outlet of flume and the weir prohibited further eggshell movement, or broke during the transport. In some trials with the coarse sand substrate, it was observed that eggshells did not move under supercritical flow, where $\tau_{0}=55.976 \mathrm{~g} / \mathrm{cm} \cdot \mathrm{s}^{2}$ to $59.117 \mathrm{~g} / \mathrm{cm} \cdot \mathrm{s}^{2}$. Under this condition, Paphitis (2001) suggested that sediment as large as medium pebbles may move. These trials were disregarded from the analyses of preferred orientation and estimation of $\tau_{\mathrm{c}}$ at their deposition. In these occasions, the eggshells were oriented concave-down in the flow with their downstream-side elevated from the bed (Figure 5). Occasionally, they exhibited sliding movement for a distance of $<1.0 \mathrm{~cm}$ at a time, yet none slid far enough to reach the hydraulic jump. Also, in a few trials with the PVC substrate, some eggshells slid concave-up all the way to the end of the flume, where $\tau_{0}$ was estimated $<1.208$ $\mathrm{g} / \mathrm{cm} \cdot \mathrm{s}^{2}$ (medium sand or smaller may move). Because it was impossible to observe whether they would move at lower $\tau_{0}$, these trials were disregarded from further analyses. One of the goose eggshells broke when the PVC substrate was used and was therefore 
disregarded for the analysis. Table 4 presents the percentage of data from a possible total of 120 (24 eggshells x 5 trials) for each substrate and eggshell taxa.

\section{Eggshell Orientation at Deposition}

For all 12 combinations of the eggshell type and substrate, there was convincing evidence that the probabilities of eggshells deposited concave-down (Figure 6) was not 0.5 regardless of eggshell types or substrates. Estimated probabilities of an eggshell deposited concave-down were $>85 \%$. (Figure 7). The estimated probabilities were consistent with the observed proportions of concave-down 2.0-5.0 cm-diameter chicken eggshells deposited in a flume on asphalt shingle $(85 \%$ and $88 \%$ under $25 \mathrm{~cm} / \mathrm{s}$ and 30 $\mathrm{cm} / \mathrm{s}$ flow velocity, respectively) (Hayward et al., 2011), which resembled the coarse sand substrate in this study. On the other hand, the estimated probabilities in this study were substantially greater than the observed proportion of the concave-down chicken eggshells deposited in a flume on a smooth plastic substrate (62\% and $57 \%$ under 25

$\mathrm{cm} / \mathrm{s}$ and $30 \mathrm{~cm} / \mathrm{s}$ flow velocity, respectively) in Hayward et al. (2011). However, this may be a result of differing methods (see discussion).

\section{Relationships of $\tau_{c}$ with Eggshell Shape and Size}

The GVF models estimated $\tau_{0}$ of each flow adequately as indicated by agreement of $\tau_{0}$ and $\tau_{\mathrm{r}}$ (Figure 8 ). Although $\tau_{0}$ and $\tau_{\mathrm{r}}$ did not match precisely, the difference between them was relatively small, and the negative relationship of $\tau_{\mathrm{r}}$ with y was consistent with 
that of $\tau_{0}$. Thus, it confirmed that $\tau_{0}$ estimates using equation 13 satisfactorily served the purpose of this study.

The relationships between $\tau_{\mathrm{c}}$ and eggshell physical properties appeared varied depending on eggshell types and substrates (Table 5, Figures 9, 10, 11, and 12). Comparing eggshell types, the results of the analysis were similar among $\mathrm{S}, \psi_{\mathrm{p}}$, and $v$ except $\psi_{\mathrm{p}}$ for ostrich eggshells, where there was no evidence for a relationship between $\tau_{\mathrm{c}}$ and $\psi_{\mathrm{p}}$, with any substrates. Comparing substrates, negative relationships existed between $\tau_{\mathrm{c}}$ and $\mathrm{S}, \psi_{\mathrm{p}}$, and $v$ on the sparse gravel substrate. This was in contrast to the generally positive relationships seen with other substrates. In addition, the evidence for relationships of $\tau_{\mathrm{c}}$ with $\mathrm{S}, \psi_{\mathrm{p}}$, and $v$ was generally inconclusive for the PVC substrate in comparison to other substrates, and only the relationship of $S$ and $v$ for ostrich eggshell was evident (Figure 12).

\section{Estimated Size of Clastic Particles Deposited with Eggshells}

Estimated $d$ of eggshell-equivalent clastic particles to be deposited with eggshells varied across types of eggshells and substrates. The smallest $d$ was $0.0680 \mathrm{~cm}$ (coarse sand) in goose eggshells on the PVC substrate, and the largest $0.504 \mathrm{~cm}$ (fine pebble) in emu eggshells on the dense gravel substrate (Table 6, Figure 13). 
Table 3: Averaged length (Ave. L), width (Ave. I), height (Ave. S), maximum projection sphericity (Ave. $\psi_{\mathrm{p}}$ ), and volume (Ave. $v$ ) for emu (EMU), goose (GSE), and ostrich (OST) eggshells.

\begin{tabular}{|cccccc|}
\hline Eggshell & $\begin{array}{c}\text { Ave. L } \\
(\mathrm{mm})\end{array}$ & $\begin{array}{c}\text { Ave. I } \\
(\mathrm{mm})\end{array}$ & $\begin{array}{c}\text { Ave. S } \\
(\mathrm{mm})\end{array}$ & Ave. $\Psi_{\mathrm{p}}$ & $\begin{array}{c}\text { Ave. } \\
\left(\mathrm{cm}^{3}\right)\end{array}$ \\
\hline \hline EMU & 26.571 & 18.754 & 2.875 & 0.242 & 0.326 \\
GSE & 25.921 & 18.471 & 4.088 & 0.303 & 0.238 \\
OST & 26.704 & 17.092 & 3.354 & 0.295 & 0.578 \\
\hline
\end{tabular}

Table 4: Percent-available data for possible total of 120 measurements (24 shells x 5 trials) for each emu (EMU), goose (GSE), and ostrich (OST) eggshell each tested on coarse sand (CS), sparse grave (SG), dense grave (DG), and polyvinyl chloride (PVC) substrate.

Eggshell

\begin{tabular}{|c|c|c|c|c|}
\hline & & EMU & GSE & OST \\
\hline \multirow{4}{*}{ 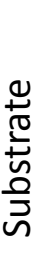 } & CS & $75 \%$ & $67 \%$ & $75 \%$ \\
\hline & SG & $100 \%$ & $100 \%$ & $100 \%$ \\
\hline & DG & $100 \%$ & $100 \%$ & $100 \%$ \\
\hline & PVC & $98 \%$ & $93 \%$ & $100 \%$ \\
\hline
\end{tabular}


Table 5: Relationships of $\tau_{\mathrm{c}}$ with natural logs of eggshell height $(\mathrm{S})$, volume $(v)$, and maximum projection sphericity $\left(\psi_{\mathrm{p}}\right)$. Each emu (EMU), goose (GSE), and ostrich (OST) tested on each coarse sand (CS), sparse grave (SG), dense grave (DG), and polyvinyl chloride (PVC) substrate. Positive relationships are indicated by a + sign, negative relationships by a - sign. If no evidence for a relationship was detected, it is indicated by "None." Values below the signs represent correlation, $\mathrm{R}^{2}$.

\begin{tabular}{|c|c|c|c|c|c|c|c|c|c|}
\hline \multirow{2}{*}{ Substrate } & \multicolumn{3}{|c|}{$\log (S)$} & \multicolumn{3}{|c|}{$\log \left(\psi_{p}\right)$} & \multicolumn{3}{|c|}{$\log (v)$} \\
\hline & EMU & GSE & OST & EMU & GSE & OST & EMU & GSE & OST \\
\hline $\mathrm{CS}$ & $\begin{array}{c}+ \\
0.809\end{array}$ & $\begin{array}{c}+ \\
0.326\end{array}$ & $\begin{array}{c}+ \\
0.646\end{array}$ & $\begin{array}{c}+ \\
0.578\end{array}$ & $\begin{array}{c}+ \\
0.676\end{array}$ & None & $\begin{array}{c}+ \\
0.773\end{array}$ & $\begin{array}{c}+ \\
0.669\end{array}$ & $\begin{array}{c}+ \\
0.607\end{array}$ \\
\hline SG & $\begin{array}{c}- \\
0.480\end{array}$ & None & $\begin{array}{c}- \\
0.366\end{array}$ & $\begin{array}{c}- \\
0.592\end{array}$ & $\begin{array}{c}- \\
0.175\end{array}$ & None & $\begin{array}{c}- \\
0.300\end{array}$ & None & 0.215 \\
\hline DG & $\begin{array}{c}+ \\
0.380\end{array}$ & $\begin{array}{c}+ \\
0.372\end{array}$ & None & $\begin{array}{c}+ \\
0.533 \\
\end{array}$ & $\begin{array}{c}+ \\
0.482\end{array}$ & None & $\begin{array}{c}+ \\
0.226\end{array}$ & $\begin{array}{c}+ \\
0.394\end{array}$ & None \\
\hline PVC & None & None & $\begin{array}{c}+ \\
0.241\end{array}$ & None & None & None & None & None & $\begin{array}{c}+ \\
0.272\end{array}$ \\
\hline
\end{tabular}


Table 6: Estimated diameter of clastic particles $(\mathrm{cm})$ to be deposited with each emu (EMU), goose (GSE), and ostrich (OST) eggshell on each coarse sand (CS), sparse gravel (SG), dense gravel (DG), and polyvinyl chloride (PVC) substrate and equivalent sediment size classification in parentheses.

\begin{tabular}{|c|ccc|}
\hline Substrate & EMU & GSE & OST \\
\hline CS & $\begin{array}{c}0.153-0.335 \\
\text { (very coarse sand }- \\
\text { very fine pebble) }\end{array}$ & $\begin{array}{c}0.139-0.352 \\
\text { (very coarse sand }- \\
\text { very fine pebble) }\end{array}$ & $\begin{array}{c}0.170-0.268 \\
\text { (very coarse sand - } \\
\text { very fine pebble) }\end{array}$ \\
\hline SG & $\begin{array}{c}0.199-0.240 \\
\text { (very coarse sand - } \\
\text { very fine pebble) }\end{array}$ & $\begin{array}{c}0.200-0.252 \\
\text { (very fine pebble) }\end{array}$ & $\begin{array}{c}0.203-0.234 \\
\text { (very fine pebble) }\end{array}$ \\
\hline DG & $\begin{array}{c}\text { 0.341-0.504 } \\
\text { (very fine pebble - } \\
\text { fine pebble) }\end{array}$ & $\begin{array}{c}\text { 0.328-0.486 } \\
\text { (very fine pebble - } \\
\text { fine pebble) }\end{array}$ & $\begin{array}{c}\text { 0.364-0.443 } \\
\text { (very fine pebble - } \\
\text { fine pebble) }\end{array}$ \\
\hline PVC & $\begin{array}{c}\text { 0.0771-0.111 } \\
\text { (coarse sand - } \\
\text { very coarse sand) }\end{array}$ & $\begin{array}{c}\text { 0.0680- 0.108 } \\
\text { (coarse sand - } \\
\text { very coarse sand) }\end{array}$ & $\begin{array}{c}\text { 0.0878-0.115 } \\
\text { (coarse sand - } \\
\text { very coarse sand) }\end{array}$ \\
\hline
\end{tabular}




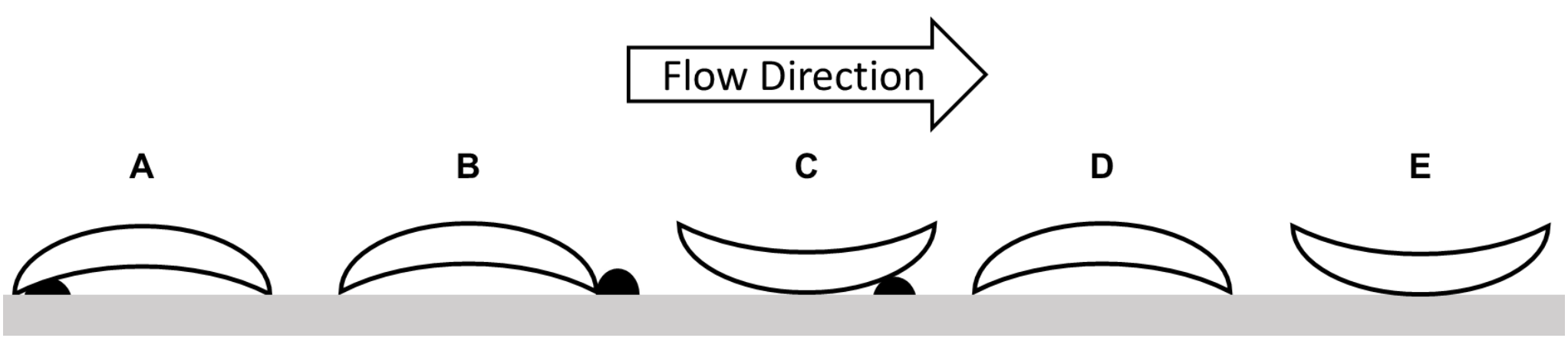

Figure 4: Schematic diagram of eggshell deposition under different conditions: A projecting particle catching upstream side of a concave-down eggshell (A), a projecting particle catching downstream side of a concave-down (B) and concave-up (C) eggshells, and flow competence insufficient to move a concave-down (D) and concave-up (E) eggshells.

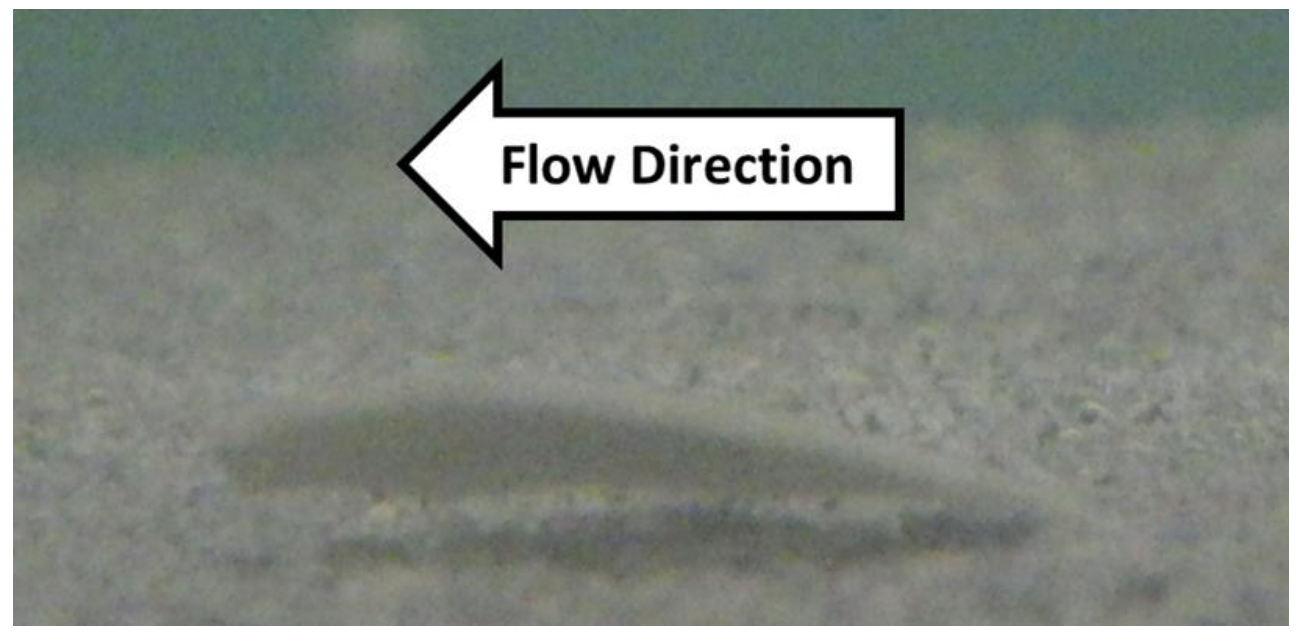

Figure 5: A stationary goose eggshell on the coarse sand substrate under a supercritical flow in an elevation view. Note the elevated edge of the shell on the downstream side of the flow. 

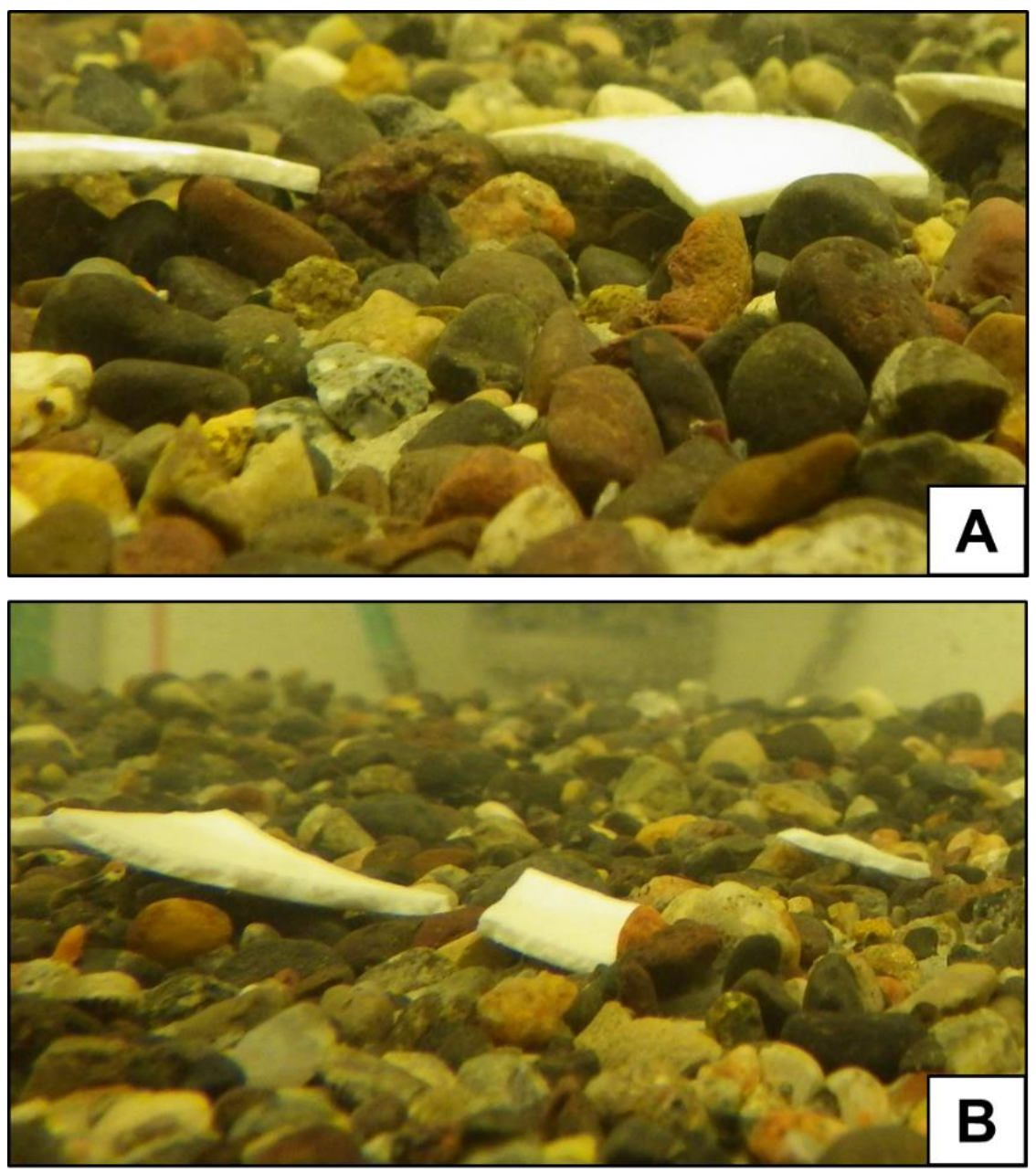

Figure 6: Examples of concave-down (A) and concave-up (B) oriented ostrich eggshells on the dense gravel substrate. 


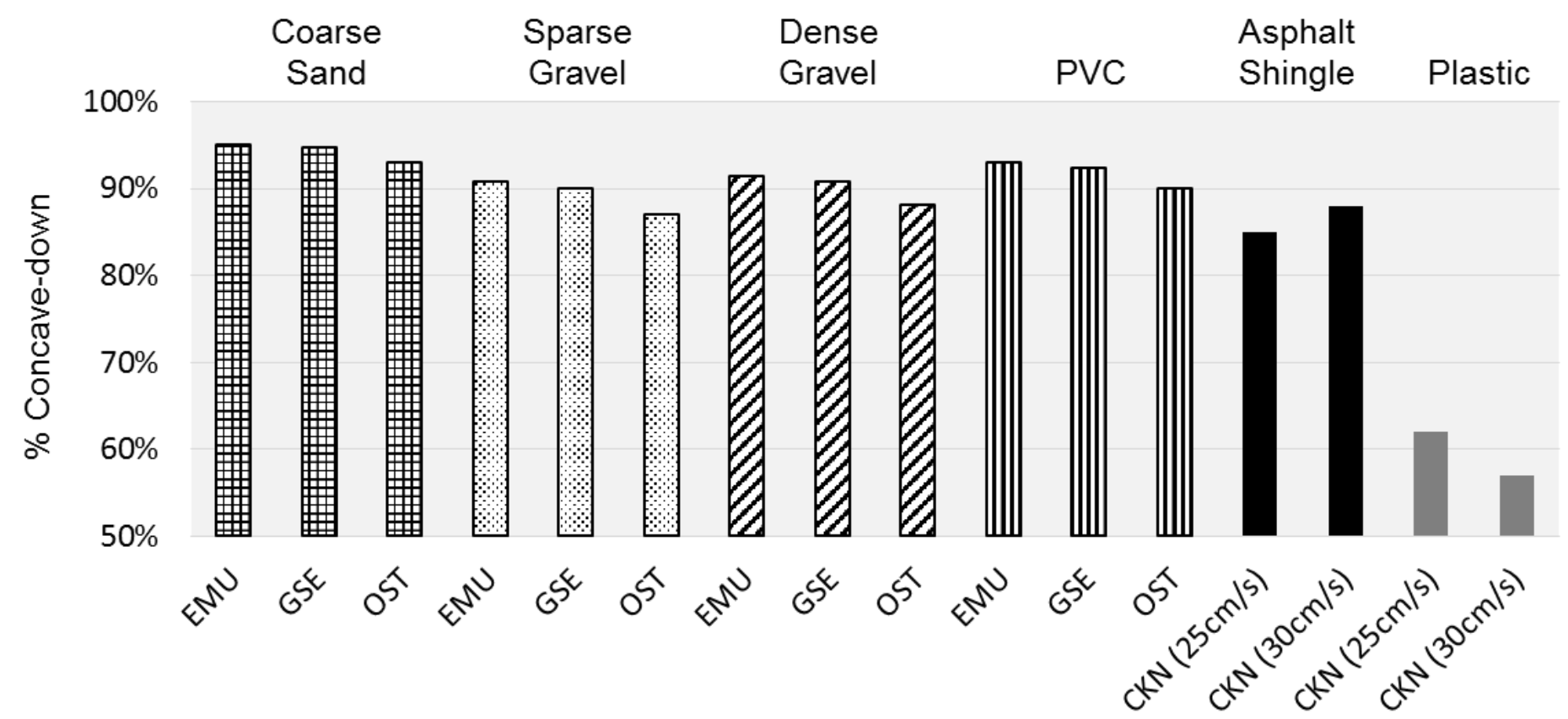

Figure 7: Estimates of probabilities that emu (EMU), goose (GSE), and ostrich (OST) eggshells are oriented concave-down after transport on coarse sand (grid), sparse gravel (dotted), dense gravel (diagonal lines), and polyvinyl chloride (PVC) (vertical lines). Observed proportions of transported chicken (CKN) eggshells $(2.5-5.0 \mathrm{~cm}$ in diameter) that exhibited concave-down orientation are also presented from the data in Hayward et al. (2011). Note that the data in Hayward et al. (2011) are observed proportions as opposed to the estimated probabilities used in the present study. The CKN eggshells were transported by water in a flume on asphalt-shingle (black fill) and plastic (gray fill) substrates at flow velocities of $25 \mathrm{~cm} / \mathrm{s}$ and $30 \mathrm{~cm} / \mathrm{s} \mathrm{(Hayward} \mathrm{et} \mathrm{al.,} \mathrm{2011).}$ 

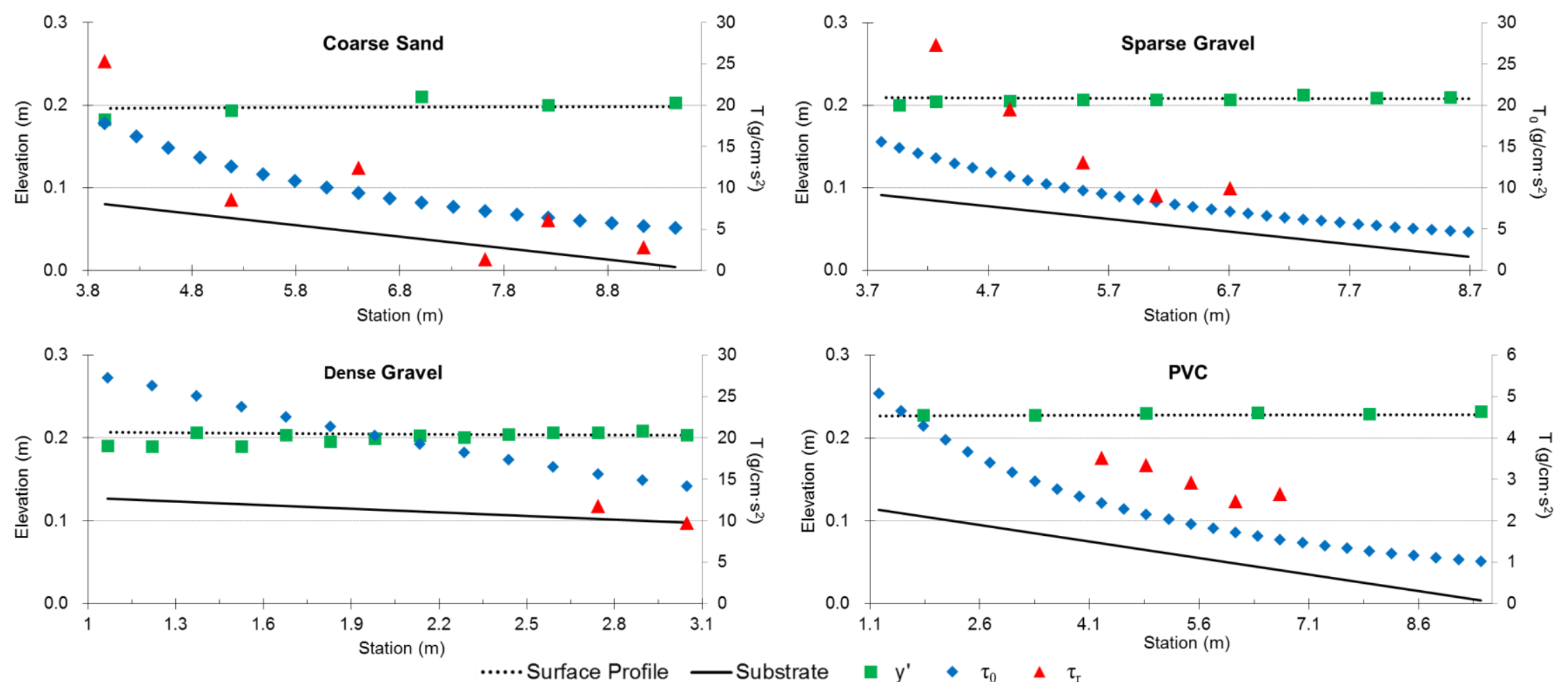

Figure 8: GVF models for each substrate. Water surface profile (black dotted line), substrate (solid line), measured depths ( $y$ ', green squares), bed shear stress ( $\tau_{0}$, blue rhombus), and Reynolds shear $\left(\tau_{\mathrm{r}}\right.$, red triangles). Station measures the distance from the inlet. Note the agreement between the surface profile and $y^{\prime}$, and $\tau_{0}$ and $\tau_{\mathrm{r}}$. 

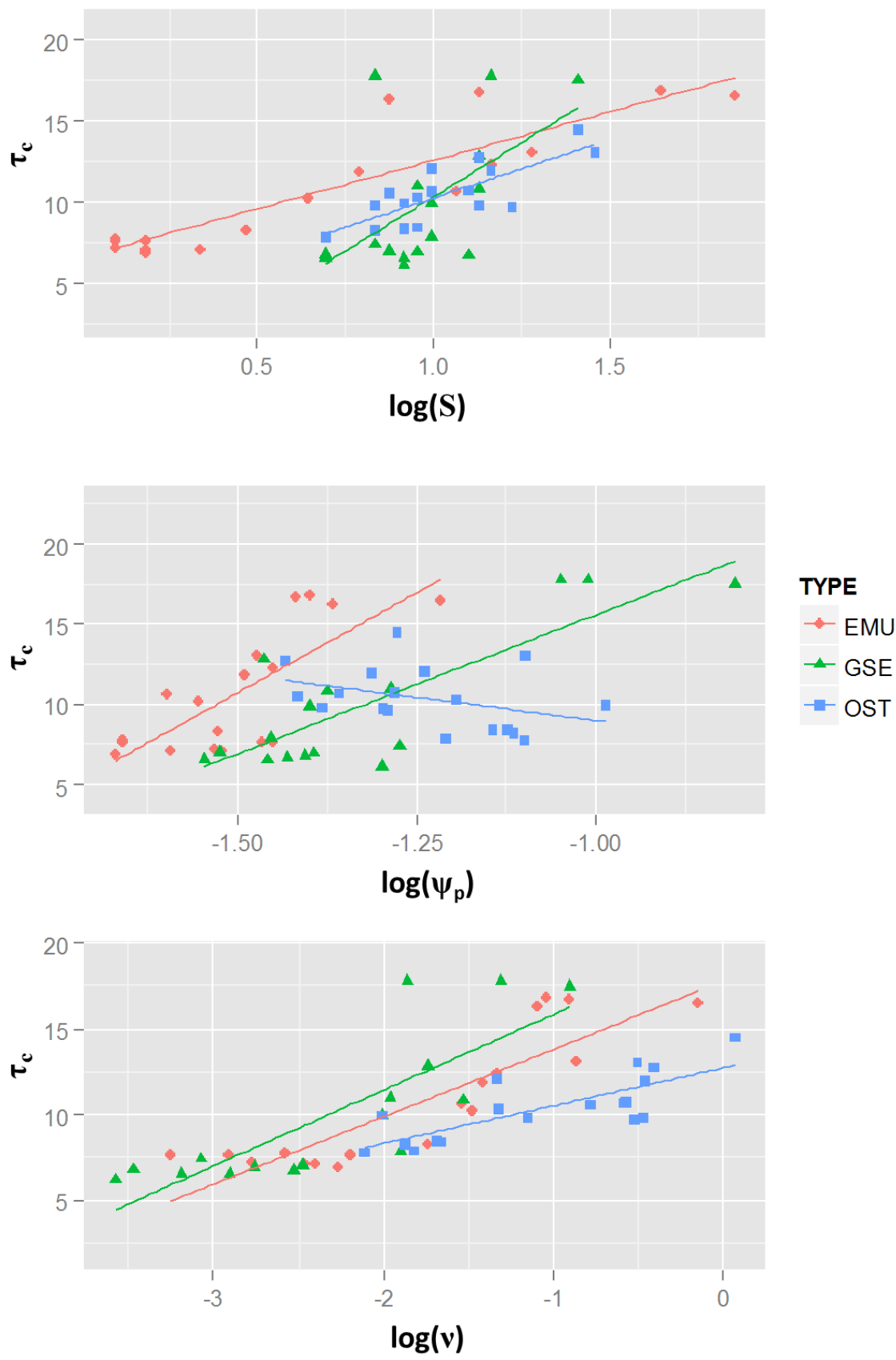

Figure 9: Plots of relationships of $\tau_{\mathrm{c}}$ with natural $\log$ of eggshell height $(\mathrm{S})$, maximum projection sphericity $\left(\psi_{\mathrm{p}}\right)$, and volume $(v)$ for emu (EMU), goose (GSE), and ostrich (OST) eggshells on the coarse sand substrate. Note that there was no evidence for the relationship of $\tau_{\mathrm{c}}$ with natural $\log$ of $\psi_{\mathrm{p}}$ for ostrich eggshells. 

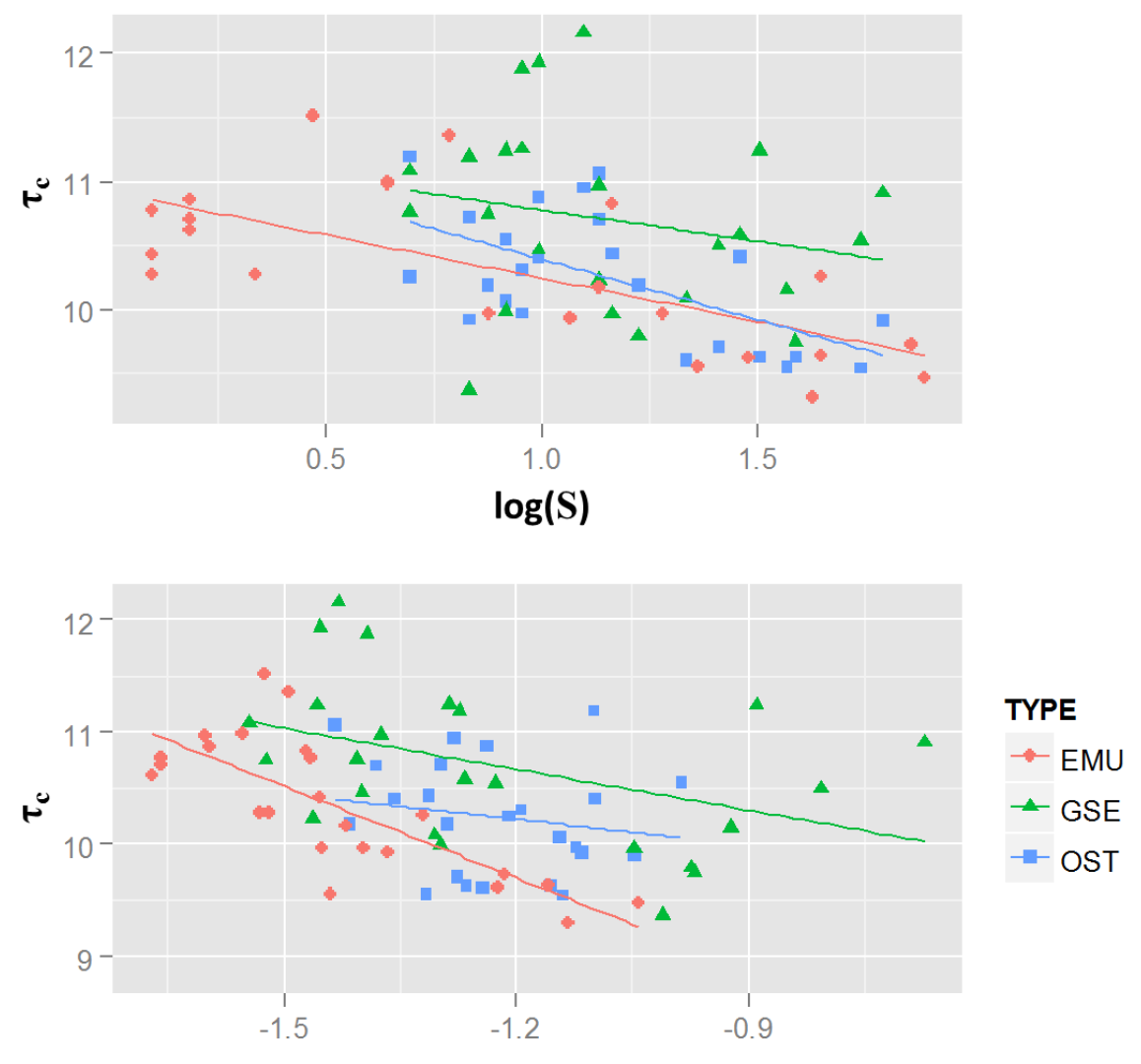

$\log \left(\psi_{\mathrm{p}}\right)$

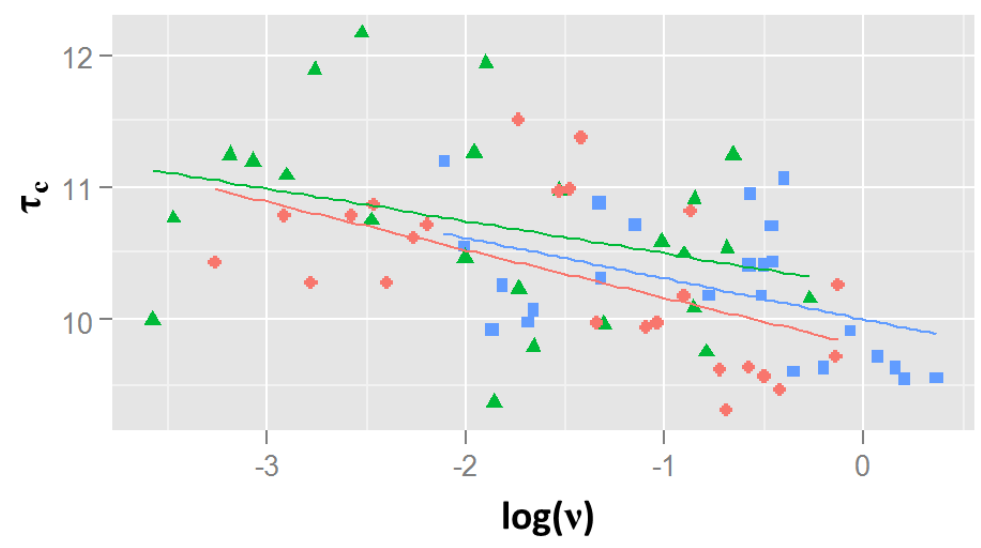

Figure 10: Plots of relationships of $\tau_{\mathrm{c}}$ with natural log of eggshell height $(\mathrm{S})$, maximum projection sphericity $\left(\psi_{\mathrm{p}}\right)$, and volume $(v)$ for emu (EMU), goose (GSE), and ostrich (OST) eggshells on the sparse gravel substrate. Note that there was no evidence for the relationships of $\tau_{\mathrm{c}}$ with natural $\log$ of $\mathrm{S}$ and $v$ for goose eggshells. Also, there was no evidence for the relationship of $\tau_{\mathrm{c}}$ with natural $\log$ of $\psi_{\mathrm{p}}$ for ostrich eggshells. 

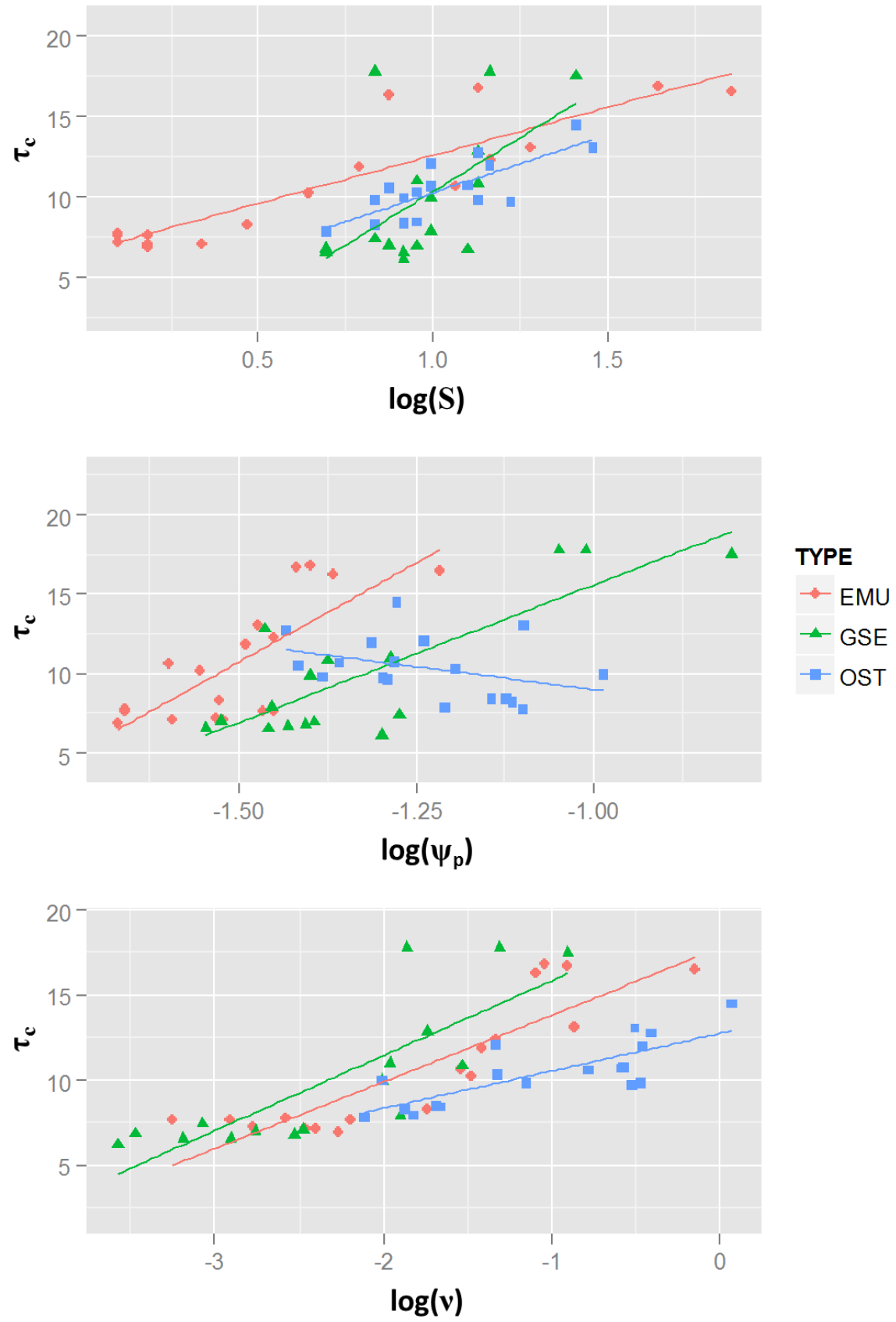

Figure 11: Plots of relationships of $\tau_{\mathrm{c}}$ with natural log of eggshell height $(\mathrm{S})$, maximum projection sphericity $\left(\psi_{\mathrm{p}}\right)$, and volume $(v)$ for emu (EMU), goose (GSE), and ostrich (OST) eggshells on the dense gravel substrate. Note that there was no evidence for the relationships of $\tau_{\mathrm{c}}$ with natural $\log$ of $\mathrm{S}, \psi_{\mathrm{p}}$, and $v$ for ostrich eggshells. 


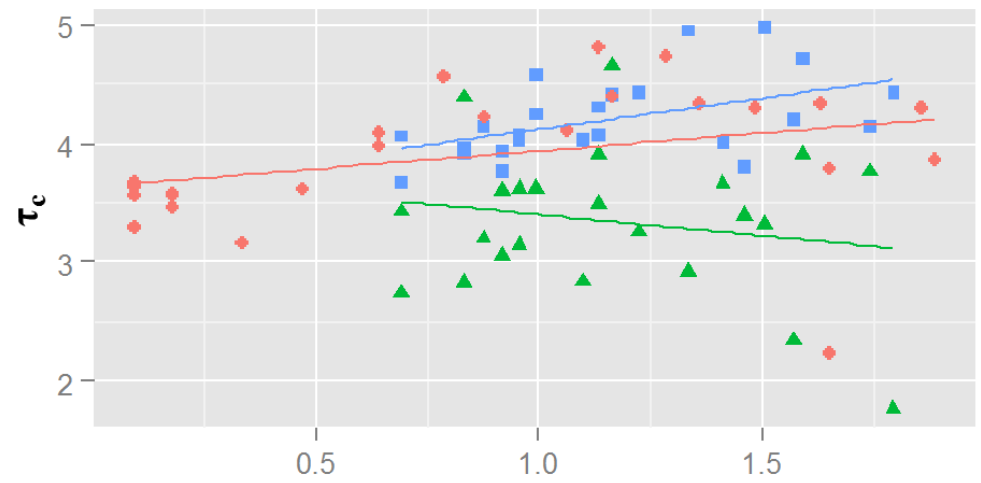

$\log (\mathbf{S})$

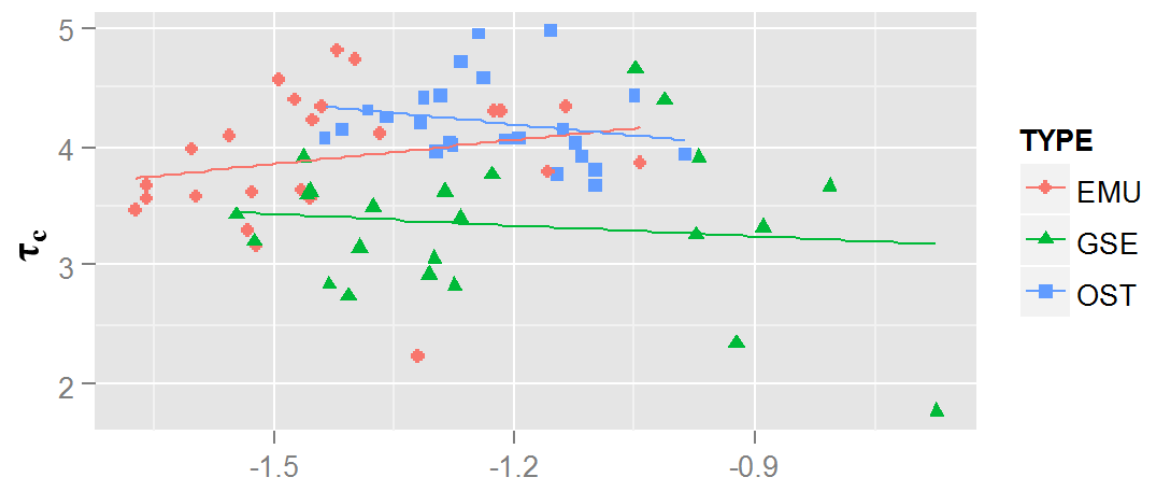

$\log \left(\psi_{p}\right)$

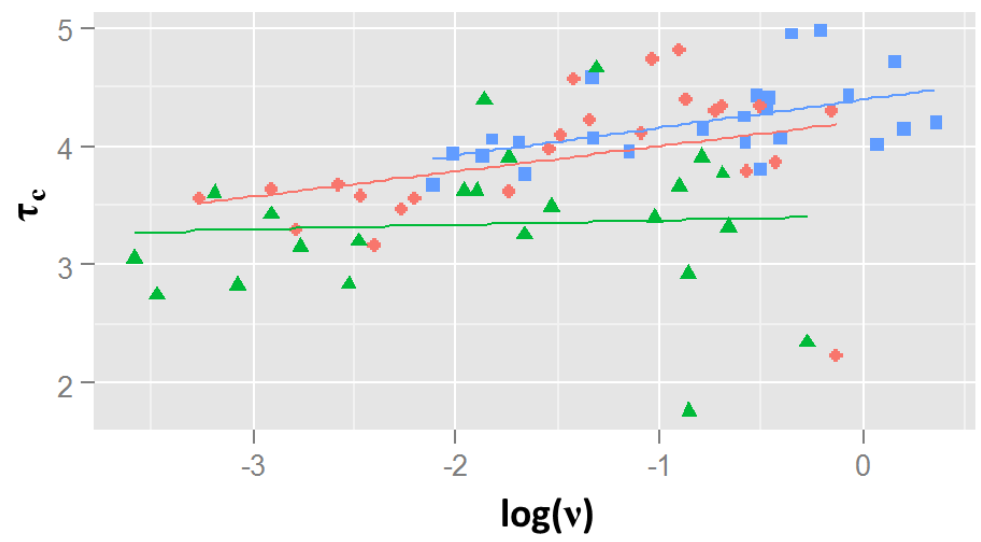

Figure 12: Plots of relationships of $\tau_{\mathrm{c}}$ with natural logs of eggshell height $(\mathrm{S})$, maximum projection sphericity $\left(\psi_{\mathrm{p}}\right)$, and volume $(v)$ for emu (EMU), goose (GSE), and ostrich (OST) eggshells on the polyvinyl chloride substrate. Evidence existed only for the relationships of $\tau_{\mathrm{c}}$ with natural $\log$ of $\mathrm{S}$ and $v$ for ostrich eggshells. 

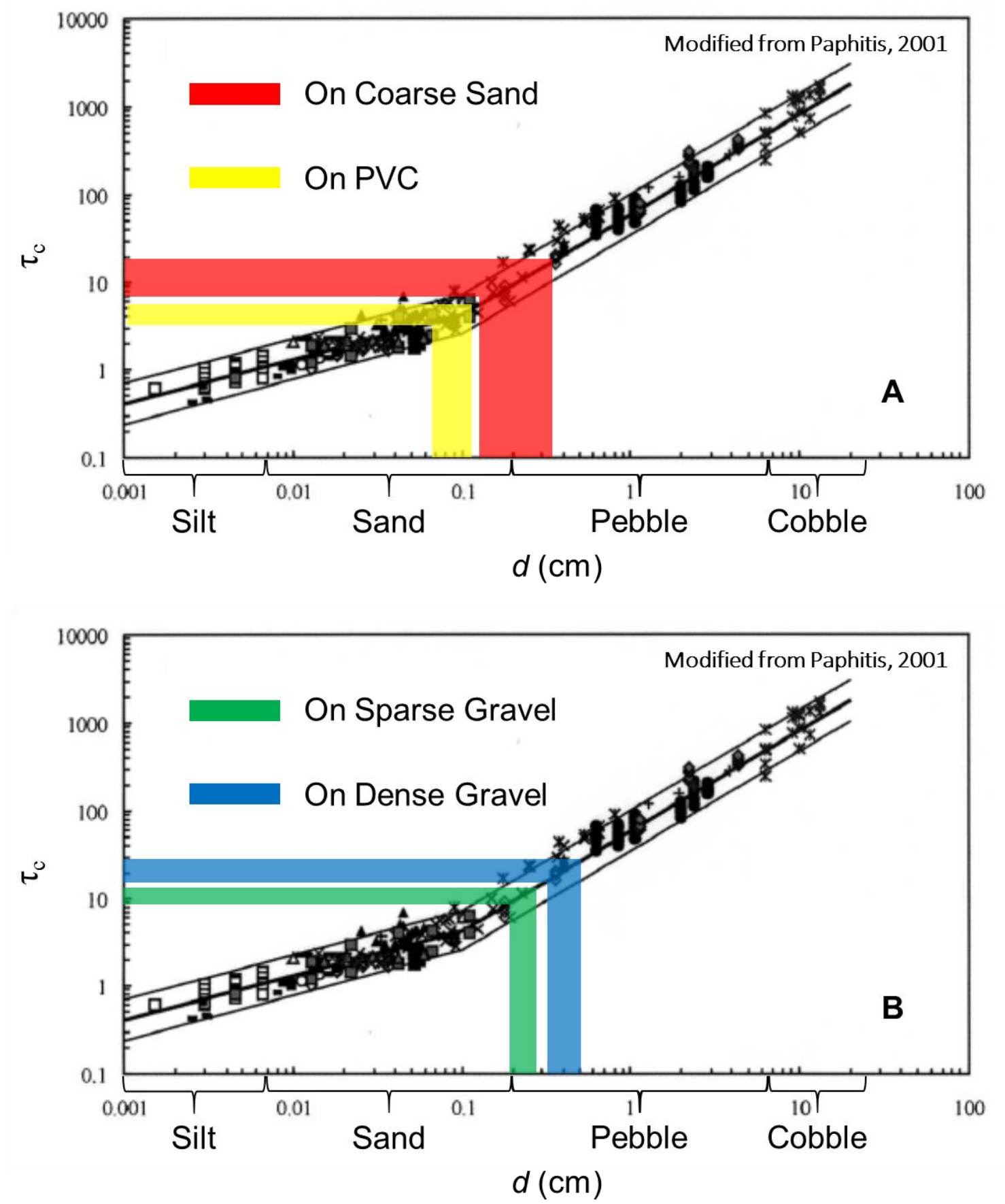

Figure 13: Estimated diameter $(d)$ of quartz particles expected to be deposited with any of the eggshells used in this study based on critical bed shear stress at eggshell deposition $\left(\tau_{\mathrm{c}}\right)$ observed on the coarse sand (red shading in A), PVC (yellow shading in A), sparse gravel (green shading in B), and dense gravel (blue shading in B) substrates. The plot was modified from Paphitis (2001). 


\section{DISCUSSION}

\section{$\underline{\text { Limitations }}$}

It should be noted that the eggshells used in this study were limited to $1.0-5.0 \mathrm{~cm}$ in diameter and $0.1-1.0 \mathrm{~cm}$ in $\mathrm{S}$. Eggshells that are greatly different in diameter and $\mathrm{S}$ from them may behave differently under hydraulic transport. For this reason, the results of this study should be only applied to naturally-occurring eggshells with similar dimensions.

\section{Eggshell Behaviors during Transport}

Unexpectedly, some eggshells did not move under a supercritical flow on the coarse sand substrate, where even medium pebbles may move. Because local flow around those eggshells was not observable, it is difficult to assess the reason for these results. In these cases, the downstream side of the shell was not in contact with the substrate (Figure 5), and therefore, a lift force seemed to be present on the downstream side. The upstream side of the shell edge was caught in the immobile substrate and further movement of the shell was perhaps prohibited. In natural settings, the presence of immobile sand-sized particle under a medium-pebble-transporting flow is unlikely; therefore, eggshells on a natural surface would probably lose underlying particles holding them and reinitiate movement. 
One might expect the platy shape of the eggshells in comparison to more spherical clastic grains to prohibit rolling. Nevertheless, observed eggshell movements were mostly by rolling on the coarse sand, sparse gravel, and dense gravel substrates.

With the PVC substrate, concave-up eggshells slid under a flow that would transport up to very fine sand, while concave-down eggshells were deposited under a flow where up to coarse sand could move. This discrepancy in $\tau_{0}$ among eggshells of different orientations suggests that concave-up eggshells are more movable than concavedown ones when eggshells can slide on a substrate. As opposed to the PVC substrate, the friction between eggshells and substrates is large in natural settings (Chow, 1959, p. 196), and eggshells would not be expected to slide frequently. Rolling was frequent on the coarse sand, sparse gravel, and dense gravel substrates, while sliding was frequent only on the PVC substrate. Therefore, sliding of concave-up eggshells at notably low $\tau_{0}$ may be uncommon in nature.

Smaller eggshells became trapped in pockets between gravels on the sparse and dense gravel substrates and often did not move further. This is perhaps due to the combination of gravel downstream of the shells acting as an obstacle and the resulting reduction of the local flow velocity below $u$ in the created pocket (Chow, 1959, pp. 196197). This observation indicates the important role of substrate particle size in the eggshell deposition. 


\section{$\underline{\text { Preferred Eggshell Orientation at Deposition }}$}

Eggshells were generally more mobile and unstable when they were oriented concave-up than concave-down regardless of substrates. Statistical analysis revealed that emu, goose, and ostrich eggshells preferentially oriented concave-down after transport. This orientation consistently occurred across substrates of differing roughness (Figure 7). These observations argue that this orientation is universally present in all types of eggshells from $1.0-5.0 \mathrm{~cm}$ in diameter and $0.1-1.0 \mathrm{~cm}$ in $\mathrm{S}$. The universality of this orientation is also supported by observations of chicken eggshells (Hayward et al., 2011) (Figure 7) as well as the preferred concave-down orientation of various disarticulated bivalve shells at deposition (e.g., Kelling and Williams, 1967; Allen, 1984). The estimates of the probabilities for the concave-down orientation were notably high for all eggshell types and substrates, indicating a high degree of reliability of the use of the preferred orientation in assessing pre-burial transport of fossil eggshells on natural substrates.

In contrast to the above results, Hayward et al. (2011) observed relatively lower proportion $(\sim 65 \%)$ of concave-down eggshells after transport on a plastic substrate (Figure 7). This is probably due to the difference in initial placement of eggshells between Hayward et al. (2011) and the present study. Hayward et al. (2011) placed half

of the eggshells concave-down and the rest concave-up before transport begun. Based on the observation in this study, eggshells transported on a very-low-roughness substrate tend to slide without change in orientation under low $\tau_{0}$. Thus, the concave-up eggshells in Hayward et al. (2011) may have only slid on the substrate until their deposition 
without changing orientation. On the other hand, in the present study, the eggshells passed through the hydraulic jump before deposition and initial orientation of eggshells was not controlled. Within and immediately after the jump, all eggshells experienced changes in their orientation, resulting in a higher proportion of concave-down than concave-up shells at deposition.

It is unknown whether the preferred concave-down orientation exists in nonchicken eggshells with proportions differing from those of the shells used here. Hayward et al. (2011) experimented with transporting 50 half chicken eggshells in a natural stream with a $u$ of $15-45 \mathrm{~cm} / \mathrm{s}$ (substrate condition not reported). Hayward et al. (2011) reported that only $14 \%$ of the 38 recovered shells exhibited concave-down orientation. This may indicate that half eggshells with a much higher $\mathrm{S}$ to diameter ratio behave differently from the flatter eggshells used in this study.

Possibly, the eggshells in this study would have exhibited preferred concavedown orientation even if the substrates had been mobile. Hayward et al. (2011) observed $85 \%$ chicken eggshell fragments $(>1.1 \mathrm{~cm}$ in diameter and smaller than a half shell) oriented concave-down after transport in a natural stream. This suggests that preferred concave-down orientation of eggshell fragments is observable on mobile, natural substrates. If this is the case, the $53: 47$ of concave-down : concave-up shell ratio of fossil eggshells in Kennedy (1997) may not support the interpretation that these eggshells were transported (Table 1). 


\section{Relationships of $\tau_{\mathrm{c}}$ with Eggshell Shape and Size}

\section{Comparison of the Relationships of $\tau_{\mathrm{c}}$ with $\mathrm{S}$}

The positive relationships between $\mathrm{S}$ and $\tau_{\mathrm{c}}$ on the coarse sand, dense gravel, and PVC substrates are somewhat puzzling (Table 5 and Figures 9, 11, and 12). Under a decelerating flow, the vertical distribution of the velocity parallel to the flow direction reaches its maximum at a point $35 \%$ of total flow height above sand and gravel bed (Emadzadeh et al., 2010). Therefore, the eggshells with larger S should be exposed to greater force by the flow due to increasing flow velocity away from the bed. This should result in deposition of the eggshells with larger $\mathrm{S}$ under smaller $\tau_{\mathrm{c}}$. Because eggshells with large $v$ also have large $S$, it is possible that the positive relationship of $v$ to $\tau_{\mathrm{c}}$ was so robust (discussed below) that true negative relationship between $\mathrm{S}$ and $\tau_{\mathrm{c}}$ was diminished in the analysis. Limited range of $\mathrm{S}$ for the eggshells in this study $(0.11-1.06 \mathrm{~cm})$ (Appendix B) also suggests that effects of differences in $\mathrm{S}$ to $\tau_{\mathrm{c}}$ for eggshell deposition were small relative to those in $v$.

There was evidence for negative relationships for emu and ostrich between $\mathrm{S}$ and $\tau_{\mathrm{c}}$ for the sparse gravel substrate (Table 5 and Figure 10); i.e., eggshells with large $\mathrm{S}$ are deposited under smaller $\tau_{0}$ and eggshells with small $\mathrm{S}$ are deposited under larger $\tau_{0}$. This is because the eggshells with small S are generally small in size and were more often trapped within pockets between gravels than the eggshells with large $\mathrm{S}$. Thus, during the flume trials, the small eggshells fell between gravel pockets soon after passing through the hydraulic jump (large $\tau_{0}$ ), whereas the larger eggshells were not trapped in those pockets due to their size relative to the pockets and moved further downstream under 
lower $\tau_{0}$. Although those pockets between gravels were also present in the dense gravel substrate, $\mathrm{S}$ of the eggshells were positively related to $\tau_{\mathrm{c}}$. This may be because the dense gravel substrate was so rough that it affected the transport regardless of size.

\section{Comparison of the Relationships of $\tau_{\mathrm{c}}$ with $\psi_{\mathrm{p}}$}

Positive relationships of $\psi_{\mathrm{p}}$ with $\tau_{\mathrm{c}}$ on the coarse sand and dense gravel substrates (Table 5, and Figures 9 and 11) indicate the eggshells with larger $\psi_{\mathrm{p}}$ become deposited at higher $\tau_{\mathrm{c}}$. The value of $\psi_{\mathrm{p}}$ can be increased by either decreasing magnitude of the product of $\mathrm{L}$ and I, or increasing magnitude of $\mathrm{S}$. The first case implies, with magnitude of $\mathrm{S}$ being fixed, that eggshells with smaller value of the product of $L$ and I have higher $\tau_{\mathrm{c}}$. The latter means, with magnitude of the product of L and I being fixed, eggshells with larger $\mathrm{S}$ have higher $\tau_{\mathrm{c}}$.

The negative relationships between $\tau_{\mathrm{c}}$ and $\psi_{\mathrm{p}}$ for the emu and goose on the sparse gravel substrate is notable (Table 5 and Figure 10). Similar relationships were observed in $\tau_{\mathrm{c}}$ and $\mathrm{S}$. Because the increase in $\mathrm{S}$ increases $\psi_{\mathrm{p}}$, and larger $\mathrm{S}$ is associated with larger size of the eggshells, $\psi_{\mathrm{p}}$ is also associated with larger shells. Therefore, the negative relationships may be explained by eggshell size and gravel-pocket interaction as in S.

Notably, no relationship between $\tau_{\mathrm{c}}$ and $\psi_{\mathrm{p}}$ was found for the ostrich. It is suspected that large shell thickness of the ostrich played a major role. However, more detailed analyses are necessary to assess the cause of absence of relationship. 
Comparison of the Relationships of $\tau_{\mathrm{c}}$ with $v$

The positive relationship between $v$ and $\tau_{\mathrm{c}}$ with the coarse sand, dense gravel, and PVC substrates (Table 5 and Figures 9, 11, and 12) suggests that larger eggshells have higher $\tau_{\mathrm{c}}$ on sandy and gravel substrates in nature. This relationship is similar to that of non-cohesive clastic grains where there is a positive relationship between diameter and $\tau_{\mathrm{c}}$ (Paphitis, 2001). It is notable that there was evidence for negative relationships for the emu and ostrich between $v$ and $\tau_{\mathrm{c}}$ with the sparse gravel substrate (Table 5 and Figure 10). These relationships are the same as those in S. As discussed previously for $S$, these relationships may be due to the size and gravel-pocket interactions. This hypothesis is further supported because $v$ is directly related to eggshell size.

Consideration of $\mathrm{S}, \psi_{\mathrm{p}}$, and $v$ with a Focus on Field Application

The negative relationships between $\tau_{\mathrm{c}}$ and $\mathrm{S}, \psi_{\mathrm{p}}$, and $v$ throughout the eggshell types on the sparse gravel substrate (Table 5 and Figure 10) highlight the role of substrates in eggshell transport. Nonetheless, potential log-linear relationships observed between $\tau_{\mathrm{c}}$ and $\mathrm{S}, \psi_{\mathrm{p}}$, and $v$ imply that natural eggshells can theoretically be sorted by hydraulic currents according to their shape and size.

Among the physical properties of eggshells studied, $v$ and $\mathrm{S}$ were better related to $\tau_{\mathrm{c}}$ than $\psi_{\mathrm{p}}$ (Table 5). It perhaps indicates that magnitude of the product of $\mathrm{L}$ and I relative to $\mathrm{S}$ of eggshells have relatively minor effects on eggshell transport than $v$ and $\mathrm{S}$. Considering that $\mathrm{S}$ of fossil eggshells may be diagenetically deformed due to lithostatic 
compaction (Hirsch and Quinn, 1990), it is advisable that $v$ be used for the field applications.

Eggshells of different size can be represented within a transported assemblage due to substrate-eggshell interaction, presence of obstacles that may be rarely preserved with eggshells (e.g. plants), and local variation in flow velocity. Therefore, in practice, sizesorting by a flow may be difficult to discern. In addition, Aslan and Behrensmeyer (1996) inferred that vertebrate bones of different size in natural channels may become mixed if they come from multiple sources. Determining whether this can be the case for eggshells requires field observations.

\section{$\underline{\text { Size of Eggshell-equivalent Clastic Particles for Eggshell Deposition }}$}

Even on the PVC substrate, where bed roughness was minimum, the eggshells had $\tau_{\mathrm{c}}$ at which coarse sand may be deposited (Table 6, Figure 13) (except those that slid concave-up at much lower $\tau_{0}$, which is probably uncommon on natural substrates). The eggshells deposited on the rougher substrates had even higher $\tau_{\mathrm{c}}$ corresponding to the deposition of larger particles, such as fine pebbles with the dense gravel substrate. Based on these observations, it is likely that fossil eggshells are commonly present as lags with coarse sediment, supporting the interpretations of transported eggshells in Erben et al. (1979) and Liang et al. (2009). The above observation is consistent with the eggshells hypothesized to be transported by Eberth (1990), which were recovered from a Upper Cretaceous coarse-grained channel deposit that included the pebble-rich mudstone. Oser (in review) further supported this hypothesis by Eberth (1990) thorough observations of 
abrasion present on these eggshells. On the other hand, fossil eggshells associated with fine sediment (Maxwell and Horner, 1994; Kennedy, 1997; Dyke et al., 2012; MorenoAzanza et al., in press) (Table 1) may have been transported by non-hydraulic mechanisms, such as mud flows.

It is also suggested that eggshell transport is typically short on fine-grained floodplains, considering the large $\tau_{0}$ required to keep eggshells transported in a flow. Thus, when pre-burial transport is evident in a fossil eggshell assemblage, the eggshells likely represent those that were laid in nearby areas (good spatial resolution). It may be even possible to preserve in situ eggshells after flooding of a nesting site if the flood has maximum $\tau_{0}$ sufficient to deposit only fine sediment.

\section{Application to Field Studies}

For fossil eggshells of similar dimensions to those studied here, one may assess their pre-depositional transport based on 1) a great majority of the eggshells exhibiting concave-down orientation, and 2) size of associated sediment equal to or larger than coarse sand on the same horizon.

For field applications, the following situations may be present in natural fluvial systems and should be considered because they were not simulated in the present study.

1) Particles forming substrates are mobile in the natural setting. Eggshells, whether deposited or intermittently moving, may act as obstacles to prevent movement of those particles and cause their deposition on the upstream side of the shells. This process may, in turn, stabilize the eggshells in the flow and initiate their burial. On the 
other hand, removal of substrates underneath eggshells may facilitate re-entrainment of these eggshells due to loss of particles that were holding them.

2) Bedforms, vegetation, and other obstacles may be present during eggshell transport and deposition. These obstacles may interfere with eggshell transport by trapping eggshells while allowing continued transport of finer materials. Because they may not be preserved in the geological record, one needs to be aware of their potential presence and influences.

3) Eggshells that are not completely saturated with water may be deposited at lower $\tau_{\mathrm{c}}$ than those that are saturated. Therefore, expected $d$ of sedimentary particles associated with those under-saturated eggshells may be somewhat smaller. 


\section{CONCLUSION}

\section{Concluding Remarks}

Although fossil eggshells often occur in fluvial deposits, where hydraulic transport of particles (whether lithic or biological) is expected, techniques to assess transport of eggshells in a fossil eggshell assemblage are underdeveloped. The present study attempted to develop such techniques through testing whether 1) preferred concave-down orientation at eggshell deposition is present in non-chicken eggs with different size and shape, 2) a relationship exists between $\tau_{\mathrm{c}}$ at eggshell deposition and eggshell size, shape, or both, and 3) the size of eggshell-equivalent particles can be estimated and applied to the fossil record. It is important to note that eggshells used in this study are $1.0-5.0 \mathrm{~cm}$ in diameter and $0.1-1.0 \mathrm{~cm}$ in $\mathrm{S}$. Thus, the application of this study to naturally occurring eggshells is limited to those of similar dimensions to those used in this study.

A preferred concave-down orientation at deposition seems to exist in the emu, goose, and ostrich eggshells regardless of the substrates upon which they are transported. Considering similar observations of preferred concave-down orientation in chicken eggshells (Hayward et al., 2011) and concave disarticulated bivalve shells (Kelling and Williams, 1967; Allen, 1984), orientation can be used to assess pre-burial transport of fossil eggshells of a wide range of shape and size.

$\mathrm{S}, \psi_{\mathrm{p}}$, and $v$ can be log-linearly related to $\tau_{\mathrm{c}}$, but the relationships depend on eggshell types and substrates. This indicates that sorting of eggshells may be recognized 
in the field by limited range of size and shape of eggshells represented in an assemblage. Generally, $v$ is the most reliable eggshell parameter to be examined when assessing the sorting of fossil eggshells, because eggshell shape can be modified by diagenetic compaction (Hirsch and Quinn, 1990). It should be cautioned that eggshell sorting may be disrupted by addition of new eggshells from multiple sources and local flow conditions (e.g., variations in local flow velocity and presence of obstacles). Considering that the relationships of $\tau_{\mathrm{c}}$ at eggshell deposition with $\mathrm{S}, \psi_{\mathrm{p}}$, and $v$ was not evident for all eggshell types transported on all substrates, it remains indeterminable whether the sorting can be used to assess eggshell transport in the field study.

It is estimated that eggshells of 1.0-5.0 cm in diameter and an $\mathrm{S}$ of 0.1-1.0 cm may be deposited with coarse sand to fine pebbles, while medium sand or smaller is more likely to be transported during the eggshell deposition. It is expected that transported eggshells can be represented more commonly as lag deposits in channel beds or on floodplain surfaces with coarse sand or larger sediment. Considering the relatively large $\tau_{\mathrm{c}}$, associated with eggshell deposition (i.e., eggshell transport requires a considerably strong flow), hydraulic transport of eggshells in natural settings such as floodplains may typically be limited to short-distances. This implies relatively good spatial resolution for transported eggshell assemblages in the fossil record. It may also be possible that eggshells are buried in situ at a nesting site after flooding if the flood has a $\tau_{0}$ lower than that sufficient to move coarse sand.

When coupled with thorough analyses of hydrodynamic indicators in eggshellbearing beds, eggshell orientation and associated sediment size can be useful clues to 
assess eggshell transport prior to burial. Because the techniques presented in this study are new, they must be further tested for their accuracy and reliability. To extend applicability of the techniques to fossil eggshells of various types, similar studies are necessary with eggshells of different diameter and $\mathrm{S}$ to diameter ratio from those used in this study. Also, experiments with mobile substrates and actualistic studies in natural environments are necessary to further test the techniques presented in this study for its application to fossil eggshells. Taphonomic studies of modern nesting sites where eggshell transport is known to occur could further test and improve the technique. Despite the many studies on fossil eggshells, taphonomic understanding of eggshells remain limited. Correct interpretation of the fossil record of eggshells will require additional studies on eggshell taphonomy. 
REFERENCES CITED 
Allen, J.R.L., 1984, Experiments on the Settling, Overturning and Entrainment of Bivalve Shells and Related Models: Sedimentology: v. 31, p. 227-250.

Aslan, A., and Behrensmeyer, A.K., 1996, Taphonomy and Time Resolution of Bone Assemblages in a Contemporary Fluvial System: The East Fork River, Wyoming: Palaios, v. 11, p. 411-421.

Behrensmeyer, A.K., 1975, The Taphonomy and Paleoecology of Pliocene Pleistocene Vertebrate assemblages East of Lake Rudolf, Kenya: Bulletin of the Museum of Comparative Zoology, v. 146, p. 473-528.

Behrensmeyer, A.K., 1982, Time Resolution in Fluvial Vertebrate Assemblages: Paleobiology, v. 8, p. 211-227.

Behrensmeyer, A.K., 1990, 3.4.3 Bones, in Briggs, D.E.G., and Crowther, P.R., eds., Paleobiology: A Synthesis: Blackwell Science Ltd, Oxford, p. 232235.

Behrensmeyer, A.K., and Hook, R.W., 1992, Paleoenvironmental Contexts and Taphonomic Modes, in Behrensmeyer, A.K., Damuth, J.D., DiMichele, W.A., Potts, R., Sues, H.D., and Wing, S.L., eds., Evolutionary Paleoecology of Terrestrial Plants and Animals: University of Chicago Press, Chicago, p. 15-136.

Behrensmeyer, A.K., Kidwell, S.M., and Gastaldo, R.A., 2000, Taphonomy and Paleobiology: Paleobiology, v. 26, p. 103-147.

Bilgil, A., 2003, Effect of Wall Shear Stress Distribution on Manning Coefficient of Smooth Open Rectangular Channel Flows: Turkish Journal of Engineering and Environmental Sciences, v. 27, p. 305-313.

Biron, P.M., Robson, C., Lapointe, M.F., and Gaskin, S., 2004, Comparing Different Methods of Bed Shear Stress Estimates in Simple and Complex Flow Fields: Earth Surface Processes and Landforms, v. 29, p. 1403-1415.

Boggs, S.Jr., 2006, Principles of Sedimentology and Stratigraphy: Pearson Prentice Hall, Upper Saddle River, 662 p.

Bridge, J.S., 1992, A Model for the Entrainment and Transport of Sediment Grains of Mixed Sizes, Shapes, and Densities: Water Resources Research, v. 28, p. 337-363. 
Buffington, J.M., and Montgomery, D.R., 1997, A Systematic Analysis of Eight Decades of Incipient Motion Studies, with Special Reference to Gravelbedded Rivers: Water Resources Research, v. 33, p. 1993-2029.

Butler, V.L., 1994, The Role of Bone Density in Structuring Prehistoric Salmon Bone Assemblages: Journal of Archaeological Science, v. 21, p. 413-424.

Carey, V.J., 2012, gee: Generalized Estimation Equation solver. R package version 4.13-18: http://CRAN.R-project.org/package=gee

Chapra, S.C., and Canale, R.P., 1988, Numerical Methods for Engineers: with Programming and Software Applications, $3^{\text {rd }}$ ed: MacGraw-Hill, Inc., U.S.A., 960 p.

Chiappe, L.M., Coria, R.A., Jackson, F., and Dingus, L., 2003, The Late Cretaceous Nesting Site of Auca Mahuevo (Patagonia, Argentina): Eggs, Nests, and Embryos of Titanosaurian Sauropods: Palaeovertebrata, v. 32, p. 97-108.

Chow, V.T., 1959, Open-Channel Hydraulics, Reissue 1988: McGraw-Hill, Inc., New York, 680 p.

Codrea, V., Smith, T., Dica, P., Folie, A., and Garcia, G., 2002, Dinosaur Egg Nests, Mammals and Other Vertebrates from a New Maastrichtian Site of the Hateg Basin (Romania): Systematic Palaeontology, v. 1, p. 173-180.

Cojan, I., Renard, M., and Emmanuel, L., 2003, Palaeoenvironmental Reconstruction of Dinosaur Nesting Sites Based on a Geochemical Approarch to Eggshells and Associated Palaeosols (Maastrichtian, Provence Basin, France): Palaeogeography, Palaeoclimatology, Palaeoecology, v. 191, p. 111-138.

Dyke, G., Vremir, M., Kaiser, G., and Naish, D., 2012, A Drowned Mesozoic Bird Breeding Colony from the Late Cretaceous of Transylvania: Naturwissenschaften, v. 99, p. 435-442.

Eberth, D.A., 1990, Stratigraphy and Sedimentology of Vertebrate Microfossil Sites in the Uppermost Judith River Formation (Campanian), Dinosaur Provincial Park, Alberta, Canada: Palaeogeography, Palaeoclimatology, Palaeoecology, v. 78, p. 1-36.

Emadzadeh, A., Chiew, Y.M., and Afzalimehr, H., 2010, Effect of Accelrating and Decelerating Flows on Incipient Motion in Sand Bed Streams: Advances in Water Resources, v. 33, p. 1094-1104. 
Erben, H.K., Hoefs, J., and Wedepohl, K.H., 1979, Paleobiological and Isotopic Studies of Eggshells from a Declining Dinosaur Species: Paleobiology, v. 5 , p. $380-414$.

Gogus, M., and Defne, Z., 2005, Effect of Shape on Incipient Motion of Large Solitary Particles: Journal of Hydraulic Engineering, v. 131, p. 38-45.

Gottfried, M.D., O’Connor, P.M., Jackson, F.D., Roberts, E.M., and Chami, R., 2004, Dinosaur Eggshells from the Red Sandstone Group of Tanzania: Journal of Vertebrate Paleontology, v. 24, p. 494-497.

Harrison, T., and Msuya, C.P., 2005, Fossil Struthionid Eggshells from Laetoli, Tanzania: Taxonomic and Biostratigraphic Significance: Journal of African Earth Sciences, v. 41, p 303-315.

Hayward, J.L., Zelenitsky, D.K., Smith, D.L., Zaft, D.M., and Clayburn, J.K., 2000, Eggshell Taphonomy at Modern Gull Colonies and a Dinosaur Clutch Site: Palaios, v. 15, p. 343-355.

Hayward, J.L., Dickson, K.M., Gamble, S.R., Owen, A.W., and Owen, K.C., 2011, Eggshell Taphonomy: Environmental Effects on Fragment Orientation: Historical Biology, v. 23, p. 5-13.

Hirsch, K.F., and Quinn, B., 1990, Eggs and eggshell fragments from the Upper Cretaceous Two Medicine Formation of Montana: Journal of Vertebrate Paleontology, v. 10, p. 491-511.

Horner, J.R., 1982, Evidence of Colonial Nesting and "Site Fidelity" among Ornithischian Dinosaurs: Nature, v. 297, p. 675-676.

Kennedy, E., 1997, Distribution of Dinosaur Eggshell Fragments in an Overbank Deposit, Two Medicine Formation, Choteau, Montana: A Preliminary Report: Abstracts with Programs - Geological Society of America, v. 29, p. 272.

Kelling, G., and Williams, P.F., 1967, Flume Studies of the Reorientation of Pebbles and Shells: The Journal of Geology, v. 75, p. 243-267.

Kim, S.B., Kim, Y.G., Jo, H.R., Jeong, K.S., and Chough, S.K., 2009, Depositional Facies, Architecture and Environments of the Sihwa Formation (Lower Cretaceous), Mid-west Korea with Special Reference to Dinosaur Eggs: Cretaceous Research, v. 30, p. 100-126. 
Krumbein, W.C., 1941, Measurement and Geological Significance of Shape and Roundness of Sedimentary Particles: Journal of Sedimentary Research, v. 11, p. 64-72.

Liang, K.Y., and Zeger, S.L., 1986, Longitudinal Data Analysis Using Generalized Linear Models: Biometrika, v. 73, p. 13-22.

Liang, X., Wen, S., Yang, D., Zhou, S., and Wu, S., 2009, Dinosaur Eggs and Dinosaur Egg-bearing Deposits (Upper Cretaceous) of Henan Province, China: Occurrences, Palaeoenvironments, Taphonomy and Preservation: Progress in Natural Science, v. 19, p. 1587-1601.

Maxwell, W.D., and Horner, J.R., 1994, Neonate Dinosaurian Remains and Dinosaurian Eggshell from the Cloverly Formation, Montana: Journal of Vertebrate Paleontolog, v. 14, p. 143-146.

Mohabey, D.M., 1998, Systematics of Indian Upper Cretaceous Dinosaur and Chelonian Eggshells: Journal of Vertebrate Paleontology, v. 18, p. 348362.

Moreno-Azanza, M., Canudo, J.I.,, and Gasca, J.M., in press, Unusual Theropod Eggshells from the Early Cretaceous Blesa Formation of the Iberian Range, Spain: Acta Palaeontologica Polonica.

Oser, S., in review, Sediment and Eggshell Interactions: Using Abrasion to Assess Transport in Fossil Eggshell Accumulations: Historical Biology.

Paik, I.S., Huh, M., and Kim, H.J., 2004, Dinosaur Egg-bearing Deposits (Upper Cretaceous) of Boseong, Korea: Occurrence, Palaeoenvironments, Taphonomy, and Preservation: Palaeogeography, Palaeoclimatology, Palaeoecology, v. 205, p. 155-168.

Paphitis, D., 2001, Sediment Movement under Unidirectional Flows: An Assessment of Empirical Threshold Curves: v. 43, p. 227-245.

Peresbarbosa, E., and Mellink, E., 2001, Nesting Waterbirds of Isla Montague, Northern Gulf of California, México: Loss of Eggs Due to Predation and Flooding, 1993-1994: Waterbirds: The International Journal of Waterbird Biology, v. 24, p. 265-271.

Pickford, M., Senut, B., and Dauphin, Y., 1995, Biostratigraphy of the Tsondab Sandstone (Namibia) Based on Gigantic Avian Eggshells; Geobios, v. 28, p. 85-98. 
R Foundation for Statistical Computing, 2012, R: A Language and Environment for Statistical Computing; 2.15.2, Vienna, Austria.

Sankey, J.T., 2005, Evidence for Fires, Aridity, Dinosaur Babies, and Eggs in Late Cretaceous of Big Bend National Park, Texas: Abstracts with Programs - Geological Society of America, v. 37, p. 528.

Sidle, J.G., Carlson, D.E., Kirsch, E.M., and Dinan, J.J., 1992, Flooding: Mortality and Habitat Renewal for Least Terns and Piping Plovers: Colonial Waterbirds: The International Journal of Waterbird Biology, v. 15 , p. 132-136.

Sneed, E.D., and Folk, R.L., 1958, Pebbles in the Lower Colorado River, Texas: A Study in Particle Morphogenesis: The Journal of Geology, v. 66, p. 114-150.

Song, T., and Graf, W.H., 1995, Bed-shear Stress in Non-uniform and Unsteady Open-Channel Flows: Journal of Hydraulic Research, v. 33, p. 699-704.

Song, T., and Chiew, Y.M., 2001, Turbulence Measurement in Non-Uniform Open Channel Flow Using an Acoustic Doppler Velocimeter (ADV): Journal of Engineering Mechanics, ASCE, v. 127, p. 219-232.

Tandon, S.K., Sood, A., Andrews, J.E., and Dennis, P.F., 1995, Palaeoenvironments of the Dinosaur-bearing Lameta Beds Maastrichtian), Narmada Valley, Central India: Palaeogeography, Palaeoclimatology, Palaeoecology, v. 117, p. 153-184.

Tomkins, I.R., 1959, Life History Notes on the Least Tern: The Wilson Bulletin, v. 71, p. 313-322.

Varricchio, D.J., 1999, A Nesting Trace with Eggs for the Cretaceous Theropod Dinosaur Troodon formosus: Journal of Vertebrate Paleontology, v. 19, p. 91-100.

Vianey-Liaud, M., Khosla, K., and Garcia, G., 2003, Relationships between European and Indian Dinosaur Eggs and Eggshells of the Oofamily Megaloolithidae: Journal of Vertebrate Paleontology, v. 23, p. 575-585.

Wadell, H., 1932, Volume, Shape, and Roundness of Rock Particles: The Journal of Geology, v. 40, p. 443-451.

Wilcock, P.R., 1992, Flow Competence: A Criticism of a Classic Concept: Earth Surface Processes and Landforms, v. 17, p. 289-298. 
Zelenitsky, D.K., and Therrien, F., 2008, Unique Maniraptoran Egg Clutch from the Upper Cretaceous Two Medicine Formation of Montana Reveals Theropod Nesting Behaviour: Palaeontology, v. 51, p. 1253-1259. 
APPENDICES 
APPENDIX A

FULL DERIVATION OF EQUATION 10 
Song and Graf (1995) proposed an equation to estimate the friction velocity $\left(u^{*}\right)$ of a gradually varying, unsteady flow (flow depth varies along the channel length and with time [Chow, 1959, pp. 5-6]) as:

$u^{* 2}=g y S_{0}+\left\{-g y \frac{\Delta y}{\Delta x}\left(1-F r^{2}\right)\right\}+\left(u \frac{\Delta y}{\Delta t}-y \frac{\Delta u}{\Delta t}\right) \quad(20)$ where $t$ is time in seconds and $\Delta y / \Delta t$ and $\Delta u / \Delta t$ designates rates of change in $y$ and $u$, respectively, with respect to $t$. In this study, the flow was gradually varied and steady, where flow depth varied along the channel length, but not with time; therefore, $\Delta y / \Delta t=\Delta u / \Delta t=0 \quad(21)$.

Further, as in Song and Graf (1995):

$u^{*}=\sqrt{\tau_{0} / \rho_{w}} \quad(22)$ and $y$ can be substituted with R (Song and Chiew, 2001). Therefore, equation 20 becomes:

$\frac{\tau_{0}}{\rho_{w}}=g R S_{0}+\left\{-g R \frac{\Delta y}{\Delta x}\left(1-F r^{2}\right)\right\}$

Rearranging equation 23 in terms of $\tau_{0}$, and substituting $\tau_{0}$ with $\tau_{\mathrm{c}}$ yields equation 10. 
$\underline{\text { APPENDIX B }}$

PHYSICAL PROPERTIES OF EACH EGGSHELL USED 
60

Emu

\begin{tabular}{|c|r|r|r|r|r|r|r|r|}
\hline No. & $\begin{array}{c}\mathrm{L} \\
(\mathrm{mm})\end{array}$ & $\begin{array}{c}\mathrm{I} \\
(\mathrm{mm})\end{array}$ & $\begin{array}{c}\mathrm{S} \\
(\mathrm{mm})\end{array}$ & $\begin{array}{l}\psi_{\mathrm{p}} \\
\mathrm{Mm}\end{array}$ & $\begin{array}{c}\mathrm{M} \mathrm{s} \\
(\mathrm{g})\end{array}$ & $\begin{array}{c}\rho \\
(\mathrm{g})\end{array}$ & $\begin{array}{c}\mathrm{V} \\
\left(\mathrm{g} / \mathrm{cm}^{3}\right)\end{array}$ & $\left(\mathrm{cm}^{3}\right)$ \\
\hline \hline 1 & 43.5 & 36.2 & 6.4 & 3.1 & 2.235 & 1.369 & 2.581 & 0.866 \\
2 & 44.1 & 19.8 & 5.2 & 1.6 & 1.464 & 0.900 & 2.596 & 0.564 \\
3 & 41.8 & 27.4 & 3.9 & 1.8 & 1.577 & 0.969 & 2.594 & 0.608 \\
4 & 36.4 & 27.3 & 6.6 & 1.7 & 1.692 & 1.037 & 2.583 & 0.655 \\
5 & 36.0 & 21.7 & 5.1 & 1.4 & 1.302 & 0.799 & 2.588 & 0.503 \\
6 & 37.4 & 20.4 & 4.4 & 1.2 & 1.253 & 0.767 & 2.578 & 0.486 \\
7 & 25.6 & 15.0 & 1.9 & 1.1 & 0.587 & 0.359 & 2.575 & 0.228 \\
8 & 39.4 & 36.0 & 5.2 & 1.6 & 2.272 & 1.393 & 2.585 & 0.879 \\
9 & 30.0 & 28.7 & 3.6 & 1.5 & 0.923 & 0.568 & 2.600 & 0.355 \\
10 & 33.1 & 25.7 & 3.2 & 1.3 & 1.101 & 0.680 & 2.615 & 0.421 \\
11 & 25.7 & 17.4 & 2.4 & 1.0 & 0.685 & 0.422 & 2.605 & 0.263 \\
12 & 28.1 & 18.1 & 2.9 & 1.0 & 0.878 & 0.542 & 2.613 & 0.336 \\
13 & 22.5 & 19.6 & 1.9 & 1.1 & 0.558 & 0.343 & 2.595 & 0.215 \\
14 & 19.4 & 11.2 & 1.2 & 0.8 & 0.268 & 0.164 & 2.577 & 0.104 \\
15 & 17.9 & 10.5 & 1.4 & 0.7 & 0.237 & 0.146 & 2.604 & 0.091 \\
16 & 23.5 & 18.2 & 2.2 & 1.0 & 0.627 & 0.384 & 2.580 & 0.243 \\
17 & 16.2 & 12.9 & 1.2 & 0.8 & 0.290 & 0.179 & 2.613 & 0.111 \\
18 & 20.6 & 12.1 & 1.6 & 0.7 & 0.455 & 0.279 & 2.585 & 0.176 \\
19 & 13.9 & 8.6 & 1.1 & 0.7 & 0.160 & 0.098 & 2.581 & 0.062 \\
20 & 32.2 & 21.1 & 3.1 & 0.9 & 1.046 & 0.641 & 2.583 & 0.405 \\
21 & 10.2 & 9.3 & 1.1 & 0.7 & 0.100 & 0.062 & 2.597 & 0.039 \\
22 & 11.7 & 8.4 & 1.1 & 0.6 & 0.142 & 0.088 & 2.606 & 0.055 \\
23 & 14.9 & 11.6 & 1.2 & 0.7 & 0.222 & 0.137 & 2.612 & 0.085 \\
24 & 13.6 & 12.9 & 1.1 & 0.8 & 0.199 & 0.123 & 2.618 & 0.076 \\
\hline
\end{tabular}


Goose

\begin{tabular}{|c|r|r|r|r|r|r|r|r|}
\hline No. & \multicolumn{1}{l|}{$\mathrm{L}$} & $\mathrm{I}$ & $\mathrm{S}$ & $\Psi_{\mathrm{p}}$ & $\begin{array}{c}\mathrm{M} \\
(\mathrm{g})\end{array}$ & $\begin{array}{c}\mathrm{M}_{\mathrm{s}} \\
(\mathrm{g})\end{array}$ & $\begin{array}{c}\rho \\
\left(\mathrm{g} / \mathrm{cm}^{3}\right)\end{array}$ & $\begin{array}{c}\mathrm{V} \\
\left(\mathrm{cm}^{3}\right)\end{array}$ \\
\hline \hline 1 & 44.0 & 40.6 & 10.6 & 3.3 & 1.887 & 1.123 & 2.470 & 0.764 \\
2 & 37.3 & 27.6 & 7.5 & 2.2 & 1.127 & 0.674 & 2.488 & 0.453 \\
3 & 40.9 & 15.9 & 9.3 & 1.3 & 1.062 & 0.635 & 2.487 & 0.427 \\
4 & 35.2 & 30.2 & 4.6 & 1.9 & 1.070 & 0.644 & 2.512 & 0.426 \\
5 & 40.5 & 34.1 & 5.9 & 1.8 & 1.271 & 0.767 & 2.522 & 0.504 \\
6 & 41.7 & 28.0 & 9.0 & 1.5 & 1.290 & 0.773 & 2.495 & 0.517 \\
7 & 32.9 & 22.8 & 4.1 & 1.3 & 0.906 & 0.545 & 2.510 & 0.361 \\
8 & 30.9 & 15.6 & 5.1 & 1.0 & 0.474 & 0.284 & 2.495 & 0.190 \\
9 & 26.7 & 19.5 & 2.9 & 1.2 & 0.544 & 0.327 & 2.507 & 0.217 \\
10 & 31.5 & 17.3 & 2.6 & 1.0 & 0.441 & 0.265 & 2.506 & 0.176 \\
11 & 28.0 & 25.1 & 5.5 & 1.3 & 0.677 & 0.406 & 2.498 & 0.271 \\
12 & 33.6 & 25.3 & 8.7 & 1.2 & 1.018 & 0.612 & 2.507 & 0.406 \\
13 & 24.6 & 15.6 & 2.4 & 0.9 & 0.335 & 0.200 & 2.481 & 0.135 \\
14 & 23.3 & 17.1 & 2.9 & 1.0 & 0.358 & 0.217 & 2.539 & 0.141 \\
15 & 16.8 & 11.3 & 1.4 & 0.8 & 0.205 & 0.121 & 2.440 & 0.084 \\
16 & 22.6 & 17.8 & 4.4 & 1.0 & 0.384 & 0.228 & 2.462 & 0.156 \\
17 & 19.2 & 18.0 & 2.1 & 1.0 & 0.371 & 0.221 & 2.473 & 0.150 \\
18 & 17.3 & 9.5 & 1.5 & 0.7 & 0.202 & 0.122 & 2.525 & 0.080 \\
19 & 10.1 & 5.9 & 1.1 & 0.6 & 0.070 & 0.042 & 2.509 & 0.028 \\
20 & 13.7 & 7.5 & 1.5 & 0.6 & 0.116 & 0.070 & 2.505 & 0.046 \\
21 & 11.2 & 10.2 & 1.2 & 0.8 & 0.102 & 0.061 & 2.470 & 0.041 \\
22 & 14.9 & 8.6 & 1.4 & 0.6 & 0.156 & 0.093 & 2.464 & 0.063 \\
23 & 14.1 & 12.4 & 1.3 & 0.8 & 0.137 & 0.082 & 2.500 & 0.055 \\
24 & 11.1 & 7.4 & 1.1 & 0.6 & 0.077 & 0.046 & 2.476 & 0.031 \\
\hline
\end{tabular}


Ostrich

\begin{tabular}{|c|r|r|r|r|r|r|r|r|}
\hline No. & $\begin{array}{c}\mathrm{L} \\
(\mathrm{mm})\end{array}$ & $\begin{array}{c}\mathrm{I} \\
(\mathrm{mm})\end{array}$ & $\begin{array}{c}\mathrm{S} \\
(\mathrm{mm})\end{array}$ & $\psi_{\mathrm{p}}$ & $\begin{array}{c}\mathrm{M} \\
(\mathrm{g})\end{array}$ & $\begin{array}{c}\mathrm{M}_{\mathrm{s}} \\
(\mathrm{g})\end{array}$ & $\begin{array}{c}\rho \\
\left(\mathrm{g} / \mathrm{cm}^{3}\right)\end{array}$ & $\begin{array}{c}\mathrm{V} \\
\left(\mathrm{cm}^{3}\right)\end{array}$ \\
\hline \hline 1 & 41.4 & 28.9 & 4.8 & 2.7 & 3.730 & 2.293 & 2.596 & 1.437 \\
2 & 38.5 & 27.8 & 4.9 & 2.2 & 3.041 & 1.869 & 2.595 & 1.172 \\
3 & 40.6 & 20.6 & 6.0 & 1.5 & 2.415 & 1.480 & 2.583 & 0.935 \\
4 & 37.2 & 16.2 & 3.8 & 1.2 & 1.833 & 1.128 & 2.600 & 0.705 \\
5 & 42.1 & 23.6 & 5.7 & 1.4 & 3.194 & 1.967 & 2.603 & 1.227 \\
6 & 36.1 & 18.0 & 4.5 & 1.1 & 2.131 & 1.314 & 2.608 & 0.817 \\
7 & 32.3 & 15.5 & 4.3 & 1.0 & 1.561 & 0.958 & 2.589 & 0.603 \\
8 & 29.2 & 19.0 & 3.4 & 1.2 & 1.540 & 0.944 & 2.584 & 0.596 \\
9 & 32.7 & 18.6 & 3.1 & 1.1 & 1.635 & 1.009 & 2.612 & 0.626 \\
10 & 27.2 & 26.1 & 3.1 & 1.4 & 1.748 & 1.080 & 2.617 & 0.668 \\
11 & 28.5 & 18.5 & 3.2 & 1.0 & 1.635 & 1.004 & 2.591 & 0.631 \\
12 & 33.0 & 23.5 & 4.1 & 1.1 & 2.796 & 1.725 & 2.611 & 1.071 \\
13 & 20.0 & 15.0 & 2.7 & 1.0 & 0.682 & 0.418 & 2.583 & 0.264 \\
14 & 19.0 & 12.8 & 2.6 & 0.9 & 0.681 & 0.415 & 2.560 & 0.266 \\
15 & 21.7 & 18.6 & 2.4 & 1.0 & 1.189 & 0.732 & 2.602 & 0.457 \\
16 & 21.8 & 11.9 & 2.3 & 0.7 & 0.819 & 0.502 & 2.584 & 0.317 \\
17 & 25.1 & 17.1 & 2.7 & 0.9 & 1.446 & 0.886 & 2.582 & 0.560 \\
18 & 23.3 & 18.0 & 3.0 & 0.9 & 1.470 & 0.906 & 2.606 & 0.564 \\
19 & 14.9 & 13.0 & 2.5 & 0.8 & 0.501 & 0.311 & 2.637 & 0.190 \\
20 & 18.3 & 8.2 & 2.3 & 0.6 & 0.396 & 0.242 & 2.571 & 0.154 \\
21 & 13.4 & 9.0 & 2.5 & 0.7 & 0.354 & 0.220 & 2.642 & 0.134 \\
22 & 17.4 & 11.3 & 2.6 & 0.7 & 0.479 & 0.294 & 2.589 & 0.185 \\
23 & 11.8 & 9.2 & 2.0 & 0.7 & 0.313 & 0.192 & 2.587 & 0.121 \\
24 & 15.4 & 9.8 & 2.0 & 0.6 & 0.419 & 0.257 & 2.586 & 0.162 \\
\hline
\end{tabular}

